Article

\title{
Changes of Extreme Agro-Climatic Droughts and Their Impacts on Grain Yields in Rain-Fed Agricultural Regions in China over the Past 50 Years
}

\author{
Min Liu ${ }^{1,2, *}$, Ying Guo ${ }^{3}$, Yanfang Wang ${ }^{4}$ and Jing Hao ${ }^{1,2}$ \\ 1 Institute of Hydrogeology and Environmental Geology, Chinese Academy of Geological Sciences, \\ Shijiazhuang 050061, China; hjing@mail.cgs.gov.cn \\ 2 Key Laboratory of Groundwater Sciences and Engineering, Ministry of Natural Resources of China, \\ Shijiazhuang 050061, China \\ 3 Key Laboratory of Agricultural Water Resources, Hebei Key Laboratory of Agricultural Water-Saving, \\ Center for Agricultural Resources Research, Institute of Genetics and Developmental Biology, \\ Chinese Academy of Sciences, Shijiazhuang 050021, China; guoy@sjziam.ac.cn \\ 4 International Science and Technology Cooperation Base of Hebei Province: Hebei International Joint Research \\ Center for Remote Sensing of Agricultural Drought Monitoring, Hebei GEO University, \\ Shijiazhuang 050031, China; wangyanfang@hgu.edu.cn \\ * Correspondence: minliu@mail.cgs.gov.cn
}

check for updates

Citation: Liu, M.; Guo, Y.; Wang, Y.; Hao, J. Changes of Extreme Agro-Climatic Droughts and Their Impacts on Grain Yields in Rain-Fed Agricultural Regions in China over the Past 50 Years. Atmosphere 2022, 13, 4. https://doi.org/10.3390/ atmos13010004

Academic Editors: Muthuvel Chelliah and Lifeng Luo

Received: 10 December 2021 Accepted: 18 December 2021 Published: 21 December 2021

Publisher's Note: MDPI stays neutral with regard to jurisdictional claims in published maps and institutional affiliations.

Copyright: (c) 2021 by the authors. Licensee MDPI, Basel, Switzerland. This article is an open access article distributed under the terms and conditions of the Creative Commons Attribution (CC BY) license (https:// creativecommons.org/licenses/by/ $4.0 /)$.

\begin{abstract}
Climate change and climate extremes and their impacts on agriculture, water resources, and ecosystems have become important issues globally. Agricultural sustainability and food security are facing unprecedented challenges due to the increasing occurrence of extreme climatic events, including, notably, extreme droughts in recent years in China. In this study, a threshold determination model of extreme agro-climatic droughts (EADs) was built based on the cumulative probability distribution functions (CDF) of an agricultural drought index-the consecutive days without available precipitation (CDWAP). The CDWAP was established by combining meteorological data with the characteristics of cropping patterns and the water requirement in different growing periods of crops. The CDF of CDWAP was obtained based on the relationship of CDWAP and its occurrence frequency. Based on the model, the spatial pattern of the thresholds of EADs and the threshold exceedance time series of EADs in 500 meteorological stations were obtained, and then changes in the frequencies and intensities of EADs in China and their impacts on grain yields in rain-fed regions during the past 50 years were analyzed. The results follow: (1) The threshold value of EADs in China gradually increased from southeast to northwest. The stations of the highest value were located in the Northwest China, with the CDWAP more than 60 days, while the lowest value was in the middle reaches of the Yangzi River, with the CDWAP less than 16 days. (2) The frequencies and intensities of the EADs increased mostly in the east areas of the Hu Huanyong line, which was also the main agricultural production region in China. The North China (NC) and Southwest China (SW) regions showed the highest increasing rates of the EADs; their frequencies and intensities were $11.3 \%$ and $2.2 \%$, respectively, for the NC region, and $9.3 \%$ and $2.7 \%$, respectively, for the SW region. (3) Case studies in the NC, SW, and SE regions indicated that there was a negative correlation between grain yields and $\mathrm{EAD}$ frequency and intensity; i.e., the low grain yields often occurred in the year with relatively higher frequency or/and stronger intensity of EADs. The correlation coefficients of grain yield and EAD were generally greater than that of merely extreme climatic droughts; therefore, the study of EAD is necessary when researching the impacts of extreme drought events on grain yield.
\end{abstract}

Keywords: extreme agro-climatic droughts; CDWAP; grain yield; North China; Southwest China; Southeast China

\section{Introduction}

According to the Fifth Assessment Report of the Intergovernmental Panel on Climate Change (IPCC), climate extremes are occurring worldwide at a rapidly increasing rate in 
an enlarged scope during the 21st century [1]. The climate models predict that the global water cycle will strengthen under the accelerating global warming, with more frequently occurring and intensified climate extreme events in many areas globally, both in extreme precipitation and extreme drought [2]. This has attracted the worldwide attention of the scientific community, governments, and the public. Among all climate extremes, extreme droughts are more prone to cause destructive disasters to agriculture, water resources, food security, and human life since they are accumulative, hidden (liable to be ignored at the initial stage), durative, seasonal, frequent, widespread, severe, and highly influential [3,4]. Statistics show that drought-induced loss accounted for more than $15 \%$ of the total loss caused by various natural disasters every year in China. According to statistics, the occurrence of droughts accounted for about one-third of the total five types of climate disasters (droughts, floods, typhoons, freezing, and dry-hot winds) in China during 1949-2005, with droughts ranked first among various climate disasters [5]. Zhang et al. (2014) also concluded that drought was the most frequent disaster during 1991-2009, with the highest proportion, 79\%, among all the agro-meteorological disasters [6].

Research on frequency and intensity of extreme drought climate events generally first needs to determine the drought index [7,8]. Many studies refer to drought index, which can be divided into two categories. The first are drought indices based on the average state of the climate change or on the relationship between regional water supply and demand. The representative indices include Palmer drought severity index $[9,10]$, standardized precipitation evapotranspiration index (SPEI) [8,11], Bhalme and Mooley drought index [12], standardized precipitation index $[7,13]$, among others. These drought indices are generally defined from the perspective of meteorology, agriculture, and hydrology, but they mostly reflect the average state of a certain period of time in the region, so the meaning of extreme events is weak. The second type of drought index mainly refers to the index adopted based on the definition of the probability of extreme climate events, e.g., consecutive dry days (CDD) in a year [14-17]. Although the second type of index is defined based on the probability of extreme events, it only belongs to the climate index and not combined with the characteristics of crop water demand in different growth periods.

As the research on global climate change expands, the impacts of climate change on food security have attracted much attention and many studies have reported the impacts of climate change and climate extremes on crop yield and food safety [18-31]. At present, the studies on the influence of climate change on agriculture mainly focus on the effects of temperature, atmospheric precipitation, and carbon dioxide on agricultural production, and most explore the effects of changes of climate mean state on food security and crop yields [23,31-39]. The research methods primarily include field experiments and crop simulation models [40-43]. Since the former is time- and finance-consuming, the latter is gradually regarded as an effective method for researching the potential influence of climate change on crops [39,44-47]. Although many studies show that global warming is favorable for the improvement of agricultural yields to a certain extent and thus has positive effects, the increase in climate extremes (i.e., extremely high temperatures, especially the extreme consecutive precipitation absence) make agricultural yields unstable and thus reduce average crop yields $[4,48,49]$. Thus, it is necessary to introduce the parameters of crop growth into the threshold determination of extreme drought events; otherwise, the threat of the climate change-induced drop in yields would be underestimated. Yang et al. (2010) [48] also pointed out that the changes in the frequency of climate extremes would possibly increase the instability and risks of agriculture in China and thus directly influence the sustainable development of agriculture in China. However, extreme droughts may not occur in the growing periods of crops. In this case, it may be difficult to discover their impact on agricultural droughts or food production [50,51]. For instance, if nonprecipitation days occur in the growing period of crops (especially in critical periods of crop water requirement) in North China, the crops may suffer droughts in the case of consecutive precipitation absence for about ten or more days. However, if nonprecipitation days happen in winter or the nongrowing period of wheat in North China, the yields of wheat may not 
be affected by the precipitation absence for only ten or more consecutive days. Instead, the soil moisture content may be only affected by the precipitation absence for multiple consecutive months before the wheat enters into the regreening period.

Based on the analysis above, the goal of this study was to build a threshold determination model of the extreme agro-climatic droughts (EADs) based on the cumulative probability distribution function (CDF) of an agricultural drought index-the consecutive days without available precipitation (CDWAP). The CDWAP was established by combining meteorological data with the cropping patterns and the characteristic of water requirement in different growing periods of crops. Additionally, the CDF of CDWAP was obtained based on the relationship of CDWAP and its occurrence frequency. In this study, based on the threshold exceedance series, the changing trends of the frequency and intensity of EADs for 500 meteorological stations were detected by relative change rate in six climatic regions of China over the past 50 years. Finally, the responses of grain yields to the frequencies and intensities of EADs in several rain-fed agricultural regions were analyzed in the case study.

\section{Study Area}

China is located in the southeast of the Eurasian continent and extends from the west bank of the Pacific Ocean to the arid area in the middle part of Central Asia. In the eastwest direction, it stretches across several regions with different moisture regime, including humid, semihumid, semiarid, and arid regions. In the south-north direction, it spans several regions with different temperatures, including tropical, subtropical, temperate, and subfrigid regions. China has a complex and varied terrain, and the relief of China is high in the west and low in the east. The ground surface consisting of three steps and the different moisture and thermal conditions jointly determine the differences of agro-climatic zones in China. In this study, China was first divided into three major natural regions according to terrain and moisture conditions, namely the monsoon region in the east, the northwest arid region in the northwest (NW), and the Qing-Tibet Plateau (QT). Among them, the monsoon region in the east serves as the primary agricultural region in China. It was further divided into four regions since it spans several thermal zones, namely the Northeast region (NE), Huang-Huai-Hai River Basin in North China (NC), Southeast region (SE), and Southwest region (SW) (Figure 1). The division concept of these six subregions was consistent with that of the Köppen-Geiger climate classification [52], which was mainly based on the hydrothermal conditions. Furthermore, the division of these six subregions also considered the characteristics of complex terrain and multimonsoon in China. It was in accordance with much previous research $[8,17]$. The SE and SW regions include the areas with abundant water and thermal conditions to the south of the Qinling-Huaihe line (i.e., the annual precipitation isoline of $800 \mathrm{~mm}$ ), with paddy fields serving as the primary farmland form [53]. The atmospheric precipitation in the SE region mainly originates from the water vapor of the Pacific Ocean transported by the southeast monsoon, while that in the SW region primarily sources from the water vapor of the Indian Ocean transported by the southwest monsoon. In contrast, the farmland in the areas to the north of the Qinling-Huaihe line (including the NE and NC regions) is dominated by dryland fields [54]. The agricultural differences between the north and south are also reflected by the differences in suitable crops and cropping systems. The crops in the NE region are dominated by spring maize, rice, and spring wheat, allowing one harvest in one year. The NC region lies in a warm temperate zone and the crops in the area primarily include winter wheat and summer maize, which allow three harvests every two years or two harvests each year. In comparison, the SE and SW regions mostly have a subtropical climate, where the crops are dominated by double- or triple-crop rice. 


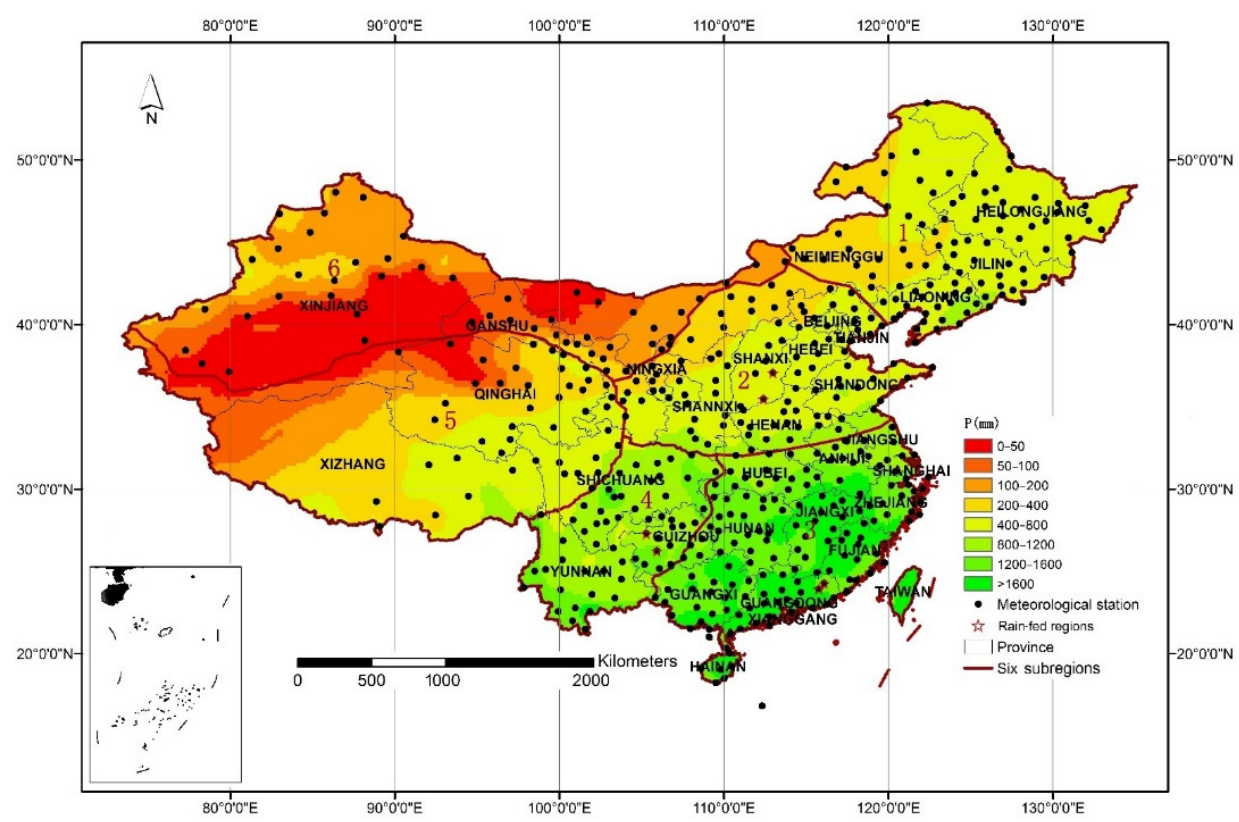

Figure 1. Study area (1-6 represent the six climatic regions of Northeast China, North China, Southeast China, Southwest China, Qing-Tibet Plateau, and Northwest China; P represents the annual mean precipitation).

\section{Data and Methods (Description of the EAD Threshold Model)}

\subsection{Data}

The meteorological data used in this study were sourced from 680 meteorological stations of the China Meteorological Administration. Observations mainly include daily precipitation and daily temperature from 1 January 1961 to 31 January 2008. There are six types of daily precipitation readings: (1) no precipitation; (2) zero precipitation (trace precipitation, daily precipitation reading less than $0.1 \mathrm{~mm}$ ); (3) precipitation from rainfall; (4) precipitation from snow and rain; (5) precipitation from pure snow; and (6) precipitation from frost, fog, and dew. All days with the latter type of precipitation are regarded as nonprecipitation days because precipitation from frost, fog, and dew is considerably low in our analysis. Data in this study were quality controlled; if there were missing observations longer than 6 days, the data series of the meteorological station was not used; for stations with missing observations less than 6 days, the missing ones were interpolated by inverse distance weighted interpolation. After filtering data for missing observations, 500 stations were considered in this analysis. Since drought events are always related to consecutive dry days, we put the data in a time-consecutive order.

The geographical distribution of crops mainly refers to An Atlas of Physical Geography of China (Version 2) [55], Agricultural Regionalization in China [56], Crop Cultivation (Version 2) [57], Crop Cultivation: Book of Southern Part (Version 2) [53], Crop Cultivation: Book of Northern Part (Version 2) [54]. Meanwhile, the data about the growing periods and the critical period of crop water requirement in each agricultural region were obtained by comprehensively considering the surveys and interviews of local peasants, advice offered by agriculture experts, and the reference books above. Moreover, the irrigation rate data was sourced from the Digital Global Map of Irrigation Areas (version 4.1) of the FAO's Global Information System on Water and Agriculture [58].

In this study, the areas with dryland fields (mainly in northern China) or paddy fields (mainly in southern China) without agricultural irrigation or irrigation rates of less than $20 \%$ were selected as rain-fed agricultural regions. Owing to the lack or incomplete grain yields per unit area, six typical rain-fed agricultural regions were selected in this study, including Yushe and Yangcheng counties in Shanxi Province, representing the NC region with a semiarid/semihumid climate, Bijie and Anshun cities in Guizhou Province representing the SW region with a humid climate, and the Meixian District and Wuhua 
County in Guangzhou Province representing the SE region with a humid climate (Figure 2). No rain-fed agricultural regions in the NE region were selected due to inadequate data on grain yields. This is also applicable to the NW and QT regions since they are not major grain-producing regions. The data on grain yields per unit area have a time span of 19 years maximally and they were mainly sourced from Guangdong Statistic Yearbook, Guangdong Rural Statistic Yearbook, Guizhou Statistic Yearbook, and Shanxi Statistic Yearbook of 1990-2008. Among them, the data in 2008 statistic yearbooks cover the statistics of 2007; the data in 2007 statistic yearbooks cover the statistics of 2006, and so on.

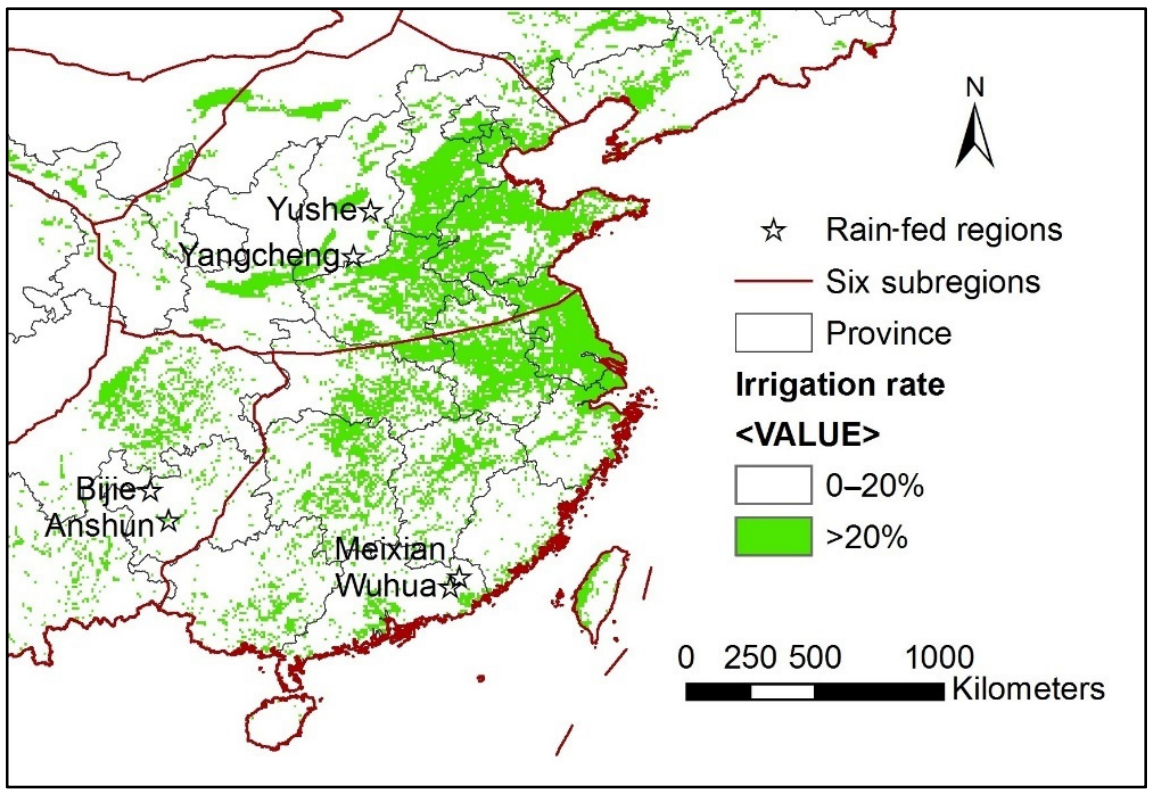

Figure 2. The typical rain-fed agriculture regions in North China, Southeast China, and Southwest China.

\subsection{Methods}

\subsubsection{EAD Threshold Model}

1. Principle and structure of the model

The EAD threshold model built in the study mainly included three modules, which were individually used to (1) select the agricultural drought index; (2) determine crop types, cropping patterns, growing periods, and critical periods of crop water requirement, and (3) determine EAD thresholds using cumulative probability distribution functions. They are described as follows.

(1) The module used to select the agricultural drought index

Agricultural drought is mainly related to the factors such as available precipitation, previous soil moisture, crop growing periods, crop water requirement, and the accumulation of previous water deficits. In this study, the CDWAP stated in a national standard of China titled Grade of Agricultural Drought (solicit opinion draft) was referred to. Meanwhile, the calculation period of CDWAP was extended to the nongrowing periods in this study since the wet or dry conditions in nongrowing periods can be used as the previous soil moisture content before crop growing, which would produce considerable influence on crop growth. Available precipitation in the nongrowing period was assumed to be greater than $1 \mathrm{~mm}$ since the nongrowing period may partially occur in winter. Meanwhile, the season-based adjustment coefficient of available precipitation was set at 0.2 for winter according to evapotranspiration characteristics in winter and the contribution of previous soil moisture content to the whole growing period of crops. The CDWAP was selected as 
the agro-climatic drought index after the calculation period was extended and relevant parameters were adjusted; the equations follow:

$$
\begin{gathered}
\text { Dnp }=\sum_{i=1}^{n} a \cdot \text { Dnp }_{i} \\
\text { Dnp }_{i}= \begin{cases}1 & P<P_{0} \\
0 & P \geq P_{0}\end{cases}
\end{gathered}
$$

where Dnp refers to CDWAP; $a$ is the season-based adjustment coefficient, which was set at 1, 1.4, 0.8, and 0.2 for spring (March, April, May), summer (June, July, August), autumn (September, October, November), and winter (December, the next January and February), respectively; $P_{0}$ denotes the available precipitation, which was set at 3,5 , and $1 \mathrm{~mm}$ for growing period, critical periods of crop water requirement, and other periods, respectively. In other words, a day with precipitation less than $5 \mathrm{~mm}$ in a critical period for crop water requirement was recognized as a day without available precipitation, and would be entered into the CDWAP calculation.

(2) The module used to identify crop types, cropping patterns, growing periods, and critical periods of crop water requirement

China boasts various widespread grain crops and they greatly differ in different geographical regions. Among them, over 20 types of common grain crops are dominated by paddy rice, wheat, and maize, which are the most widespread and their total production accounts for more than $86 \%$ of the national grain yield. Therefore, only these three crops were considered in the model to simplify calculations. To calculate CDWAP in a certain region, it was necessary to initially determine the crop types and cropping patterns in the region since growing periods and critical periods of crop water requirement vary with crop types and cropping patterns.

Crop types and cropping patterns are closely related to geographical locations and thermal conditions. Based on the daily temperature data during 1971-2000 (the World Meteorological Organization standard climate period [59]), the authors analyzed the spatial pattern of the mean annual temperature of meteorological stations across China and simplified it into five major grain cropping pattern regions, as follows (Figure 3). (1) The area with a mean annual temperature of $\leq 10{ }^{\circ} \mathrm{C}$ in Northeast China. It is the major producing region of spring maize, and the cropping pattern is generally monocropping with one harvest per year. (2) The major producing area of spring wheat with a mean annual temperature of $\leq 10{ }^{\circ} \mathrm{C}$. It includes areas with a mean annual temperature of $\leq 10^{\circ} \mathrm{C}$, except for Northeast China, and its cropping pattern is generally monocropping with one harvest per year. (3) The major producing area of winter wheat and summer maize rotation system with a mean annual temperature of $10-15^{\circ} \mathrm{C}$. It consists of most of North China, Huang-Huai-Hai Plain, Southern Xinjiang, and partial areas in Southwest China, and its cropping pattern generally has two harvests per year. (4) The area with a mean annual temperature of $15-21{ }^{\circ} \mathrm{C}$ and crops dominated by double-crop rice. It mainly includes the middle and lower reaches of the Yangtze River in Southeast China, and the region's cropping pattern is generally monocropping with two harvests per year. (5) The area with a mean annual temperature of $\geq 21{ }^{\circ} \mathrm{C}$ and the crops dominated by triple-crop rice. It mainly includes Hainan Island and the southern parts of Guangdong and Guangxi provinces, and its cropping pattern is generally monocropping with three harvests per year. By comparison with the agro-climatic zoning map in the An Atlas of Physical Geography of China (Version 2) and the thermal condition zoning map under the cropping system of China, the simplified geographical distribution framework and cropping patterns of grain crops described above are reasonable and thus could be used to determine crop types and cropping patterns in the EAD threshold model. 


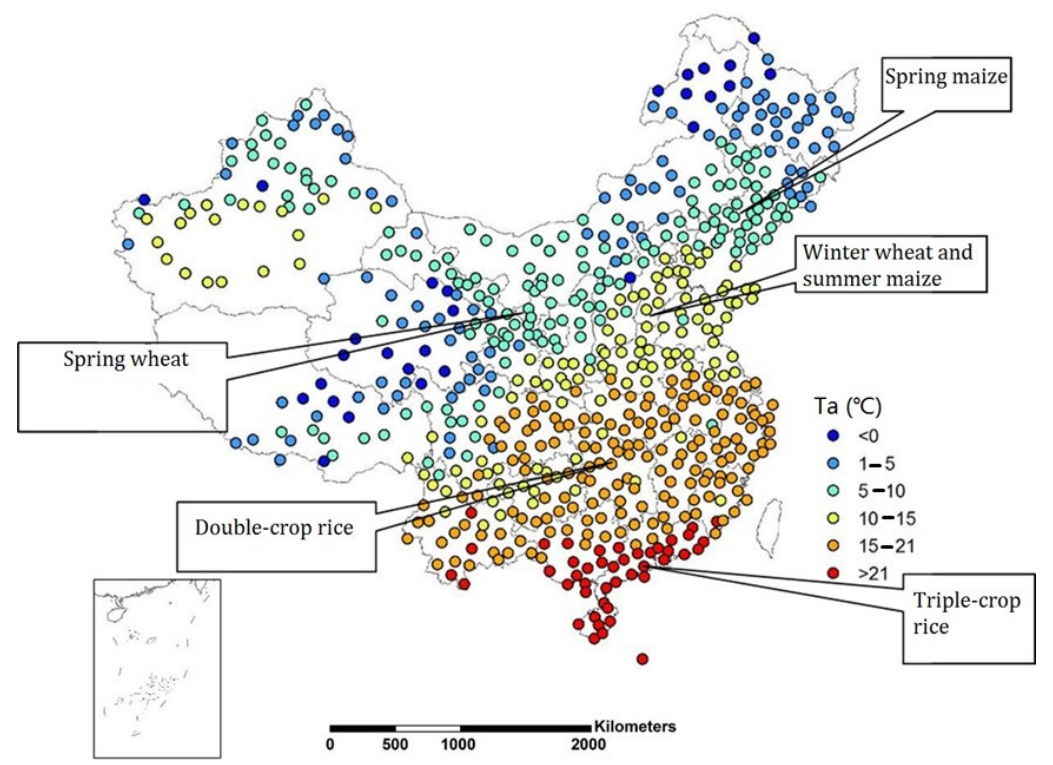

Figure 3. Spatial distribution of mean annual temperature and main grain crop patterns in China (Ta-mean annual temperature based on the data from 1 January 1971 to 31 December 2000).

Afterward, it was necessary to determine the growing periods and critical periods of crop water requirement of major grain crops in the five agricultural regions. The growing period of a crop generally starts when the crop begins to regreen or grow and ends when it enters the wintering period or is harvested. The critical periods of crop water requirement for the three major grain crops are shown in Table 1. According to surveys and interviews of local peasants in these regions, advice offered by experts in agricultural science and cultivation, and reference books [53-57], the authors finally determined the regional average beginning and ending dates of the growing periods and their corresponding critical periods of water requirement in each region (Table 2 ).

Table 1. Critical periods of water requirement for the three main grain crops in China.

\begin{tabular}{cc}
\hline Crops & Critical Period of Water Requirement \\
\hline Wheat & booting stage to heading stage \\
Rice & booting stage to flowering stage \\
Corn & booting stage to milk-ripe stage \\
\hline
\end{tabular}

Note: Classification of agricultural drought category, National Standards of the People's Republic of China, GB/T 32136-2015.

Table 2. Date determination of the growing period and the critical period of the main crop water requirement in China.

\begin{tabular}{|c|c|c|c|c|c|}
\hline Ta & \multicolumn{2}{|c|}{$\mathrm{Ta}<10$} & \multirow{2}{*}{$\begin{array}{l}\qquad 10<\mathrm{Ta}<15 \\
\text { Winter Wheat and } \\
\text { Summer Maize }\end{array}$} & \multirow{2}{*}{$\begin{array}{c}15<\text { Ta }<21 \\
\text { Double-Crop Rice }\end{array}$} & \multirow{2}{*}{$\begin{array}{c}\text { Ta }>21 \\
\text { Triple-Crop Rice }\end{array}$} \\
\hline $\begin{array}{c}\text { Crop Planting } \\
\text { Patterns }\end{array}$ & Spring Corn (NC) & $\begin{array}{l}\text { Spring Wheat } \\
\text { (NW) }\end{array}$ & & & \\
\hline Growing period St. & $04-25$ & 03-15 & 03-15 & 04-05 & 04-05 \\
\hline CPCWR St. & 08-01 & $05-25$ & 04-20 & $06-01$ & 06-01 \\
\hline CPCWR E. & 09-05 & $06-20$ & 05-10 & $06-20$ & 06-20 \\
\hline CPCWR St. & & & 08-10 & 09-01 & 09-01 \\
\hline CPCWR E. & & & 09-15 & 09-20 & 09-20 \\
\hline CPCWR St. & & & & & $12-25$ \\
\hline CPCWR E. & & & & & 02-05 \\
\hline Growing period E. & 09-10 & 08-05 & 09-30 & $10-20$ & $03-05$ \\
\hline
\end{tabular}

Note: St.-start date, E.-end date; Ta-mean annual temperature; CPCWR-critical period of crop water requirement. 
(3) The module adopted to determine EAD thresholds using cumulative probability distribution functions

CDWAP would exacerbate the threats of drought to crops; the longer the CDWAP, the greater the probability of developing extreme droughts. This study first established the cumulative probability distribution function of the CDWAP in each meteorological station, and then a supposed level of CDWAP was determined as the EAD threshold. That was, if an observed CDWAP was longer than the supposed CDWAP, it could be called an EAD event. The specific process was as follows. The CDWAP series was obtained by arithmetic progression, i.e., 2, 5, 8, . , and the corresponding occurrence times of each CDWAP element during 1971 to 2000 were computed. Based on the relationship between the CDWAP series and its occurrence frequency series, the probability density function of CDWAP could be established, and then the cumulated distribution function obtained. The corresponding value of 95th percentile CDWAP was chosen as the EAD threshold, i.e., if an observed CDWAP was longer than the corresponding 95th percentile CDWAP value, it could be called an EAD event [17].

\section{Calculation process of the EAD threshold model}

The cumulative probability distribution function of the CDWAP of each meteorological station was established based on the drought index (CDWAP), the relationship between the geographical distribution of major grain crops and mean annual temperature, and the time parameters of the major grain crops in each region (i.e., growing period and critical periods of crop water requirement). The EAD thresholds of all the stations were then determined assuming that the EAD threshold was the CDWAP corresponding to $p=95 \%$. Figure 4 shows the flowchart used to calculate EAD thresholds. The input included the station number, mean annual temperature, longitude, and latitude of each station; precipitation data from 1 January 1971 to 31 December 2000 for each station; major grain crops corresponding to the mean annual temperature; and the cropping patterns and different growing periods of the crops. The output was the EAD thresholds of all the stations.

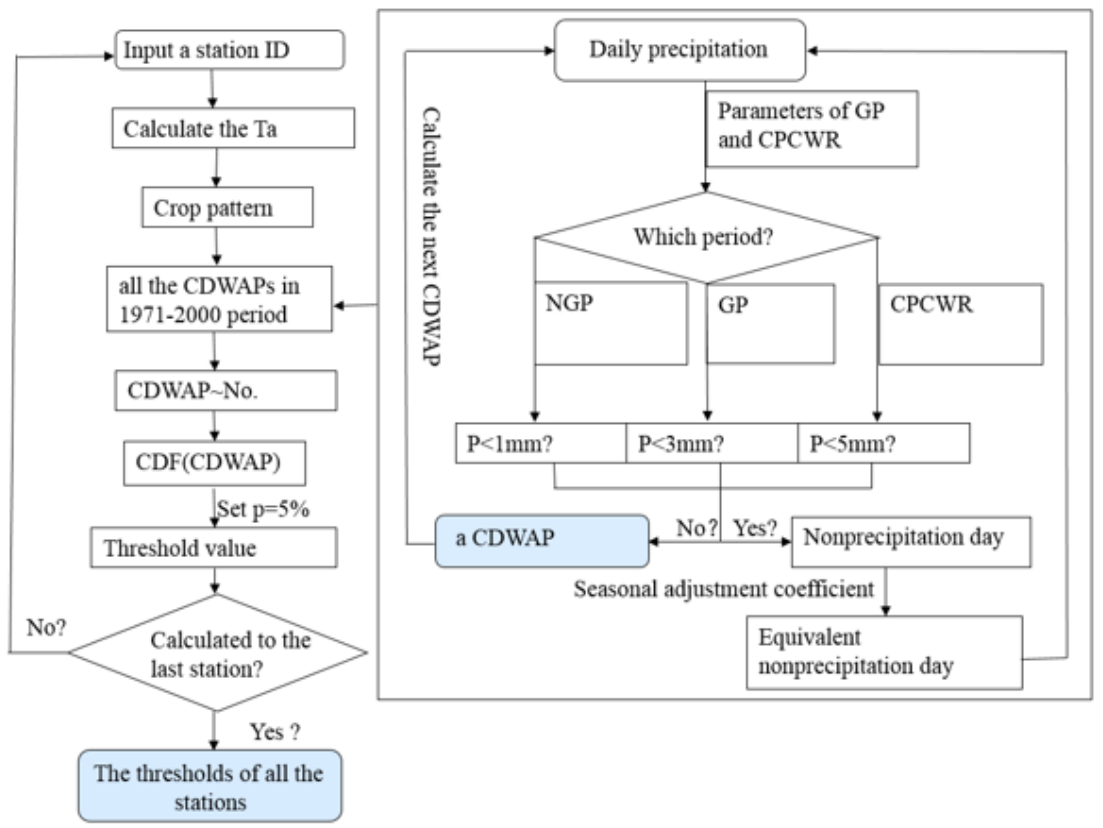

Figure 4. EADs threshold model calculation flowchart. ( $\mathrm{P}$-daily precipitation; Ta-mean annual temperature; CDWAP — consecutive days without available precipitation; No.-number of occurrences; $\mathrm{CDF}$ - cumulative probability distribution function; $\mathrm{p}$-percentile; $\mathrm{GP}$ - growing period; $\mathrm{NGP}$-non-growing period; CPCWR—critical period of crop water requirement). 
The flowchart can be briefly described as follows. (1) Input a meteorological station ID. Then determine the major grain crops in the region of the station and their cropping patterns based on the temperature range of the station. (2) Under the cropping pattern, input the 1 January 1971 to 31 December 2000 daily precipitation data in chronological order. Then determine whether no available precipitation occurred on the initial day according to the water requirement of the stage in which the date falls. If yes, then calculate the equivalent nonprecipitation days according to the season-based adjustment coefficient. Then input the precipitation of the next day and repeat the procedure in this step until one available precipitation day occurred. In this way, a CDWAP was obtained. (3) Repeated the second step from the next day of the end date of the previous CDWAP calculation process, until all CDWAPs in the whole basic period (1971-2000) are determined. (4) Establish an arithmetic progression series of CDWAPs, count the corresponding occurrence times of each CDWAP element during 1970-2000, and then calculate the probability density function of CDWAP. (5) Work out the cumulative probability distribution function of CDWAP based on the probability density function of CDWAP. Then determine the CDWAP corresponding to the percentile $p=95 \%$, which was the EAD threshold of the station. After this, repeat all of the steps in turn until the EAD thresholds of all the stations are obtained.

\subsubsection{Change-Point Analysis}

Moving $t$-test was employed to detect the trends and change-point years of EADs in this study. It is one of the most commonly used methods for testing a hypothesis based on a difference between sample means [60]. The formula for calculation follows:

$$
t=\frac{\overline{x_{1}}-\overline{x_{2}}}{\mathrm{~s} \sqrt{\frac{1}{\mathrm{n}_{1}}+\frac{1}{\mathrm{n}_{2}}}},
$$

in which

$$
\mathrm{s}=\sqrt{\frac{\mathrm{n}_{1} \mathrm{~s}_{1}^{2}+\mathrm{n}_{2} \mathrm{~s}_{2}^{2}}{\mathrm{n}_{1}+\mathrm{n}_{2}-2}},
$$

where $\bar{x}_{i}, \mathrm{~s}_{\mathrm{i}}$, and $\mathrm{n}_{\mathrm{i}}$ are the mean, standard deviation, and length of two subsamples. The numerator of Equation (3) is the difference between the two subsequences, the denominator of Equation (3) is the estimate of the dispersion, $n_{1}+n_{2}-2$ is the degrees of freedom.

The moving $t$-test is done by selecting two adjacent subsamples of fixed length, then slide backwards in turn, finally taking the best change-point [61]. Compared to the Student's $t$-test, the moving $t$-test can estimate multiple change-points, and estimate the main trend of the series according to the property (positive or negative) of the maximum changepoint $|t|_{\text {max }}$, i.e., when the $t$ value of the maximum change-point is negative; it indicates an increasing change-point, while positive indicates a decreasing one. Let the length of the subsample series be 10, for a fixed significance level $\alpha=0.1$ in this present paper, the corresponding critical value $t_{\alpha}=1.73$. If the calculated value $|t|>t_{\alpha}$, it indicates a significant trend, while $|t|<t_{\alpha}$ describes a nonsignificant trend.

\subsubsection{Calculation of Climatic Yield}

Agricultural production and grain yields per unit area are influenced by various complex factors, which could be divided into two categories, namely natural factors and human factors. The natural factors mainly include the mean state of climate change and the extreme climatic extremes, while the human factors include policies, production technologies, management levels, cropping patterns, irrigation activities, and variety cultivation [62,63]. Since rain-fed agricultural regions are generally not affected by irrigation, the impacts of EADs on grain yields in these regions could be analyzed after removing the trend yields attributable to the improvement in technology, plant breeding, and cropping patterns from grain yields. Therefore, rain-fed agricultural regions were selected to analyze the impacts of EADs on grain yields in this study. 
Grain yields were divided into trend yield and climatic yield in this study (Figure 5). The trend yield is mainly related to the improvement in the technologies (mechanization and fertilization) and management level of agricultural production and the improvement in cropping patterns and variety cultivation, which was a stable increased yield [63]. Furthermore, global warming and the greenhouse effect were also attributed to a fraction of the stable increasing trend. The climatic yield covered the impacts of climatic elements with interannual fluctuations and climate extremes on grain yield and the random yield. In this study, the trend yield was removed by using linear trend fitting and then the response of climatic yield to EADs was analyzed. Given that EADs were likely to occur in the years with low annual precipitation, the climatic yield induced by extreme drought events included a part of the climatic yield caused by interannual fluctuations of precipitation.

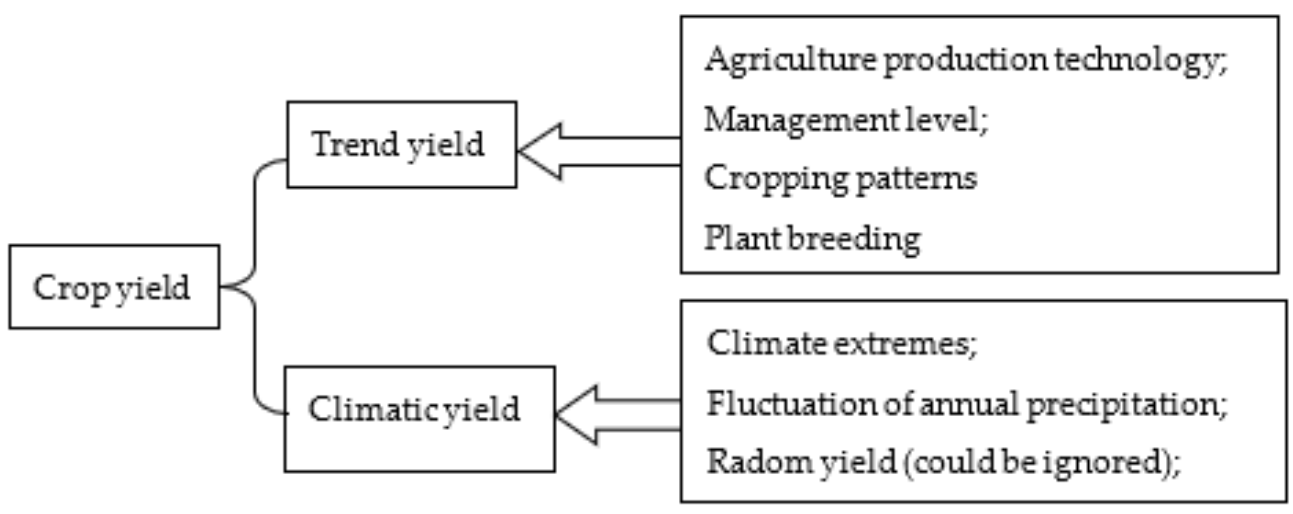

Figure 5. Grain yield decomposition flowchart.

\section{Results}

\subsection{Spatial Pattern of EAD Thresholds}

The station-based spatial distribution of EAD thresholds in China was determined by using the EAD threshold model, the index was CDWAP, and the unit was days (Figure 6). Generally, the EAD threshold values tended to decrease from northwest to southeast. The maximum EAD threshold was in the desert of the northwestern arid regions, which was generally greater than 60 days. In contrast, the minimum EAD threshold appeared in the river basin of the middle reaches of the Yangtze River, which was less than 16 days in general. Furthermore, the EAD thresholds of North China and humid regions were 20-40 days and 16-20 days, respectively, in general. All these were similar to the distribution pattern of extreme climatic drought (ED) thresholds obtained by Liu et al. [17], except that the thresholds in this study were higher overall since they were determined based on the index of CDWAP, while ED threshold was determined by consecutive dry days (CDD) from the perspective of climatology. The ED threshold also adopted the corresponding value of the 95th percentile of the cumulative probability distribution function of CDD.

\subsection{Spatial-Temporal Pattern of EAD Variation}

Once the threshold was defined, the threshold exceedance time series was estimated to obtain EAD indices. For the frequency of EAD, we took the times of their annual occurrence as the index. For the intensity of EAD, we chose the annual maximum consecutive dry days without available precipitation (MCDWAP) as the index instead of the average intensity of threshold exceedance due to the average CDWAP may weaken the meaning of the "extremes". 


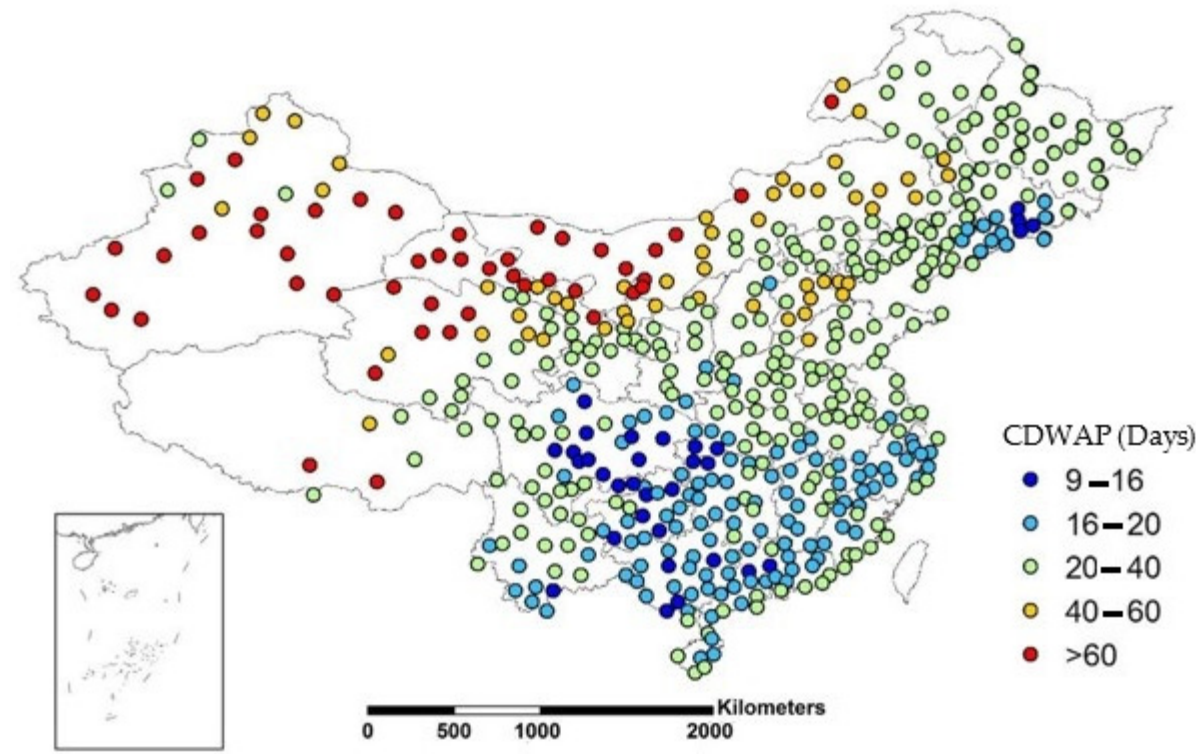

Figure 6. Spatial distribution of EADs thresholds (CDWAP—consecutive days without available precipitation).

\subsubsection{Station-Based Spatial Patterns of EAD Relative Change Rates}

The EAD series (the series exceeding EAD thresholds) were divided into two periods (1961-1984 as the reference period and 1985-2007 as the research period) to analyze the change rates of the frequency and intensity of EADs during 1985-2007 relative to those during 1961-1984 (i.e., the ratio of the differences in annual change rates between the two periods to the annual change rates of the former period), as shown in Figure 7a (frequency) and Figure $7 \mathrm{~b}$ (intensity). Positive relative change rates in both frequency and intensity implied EADs occurred more with stronger intensity in the research period, and vice versa.
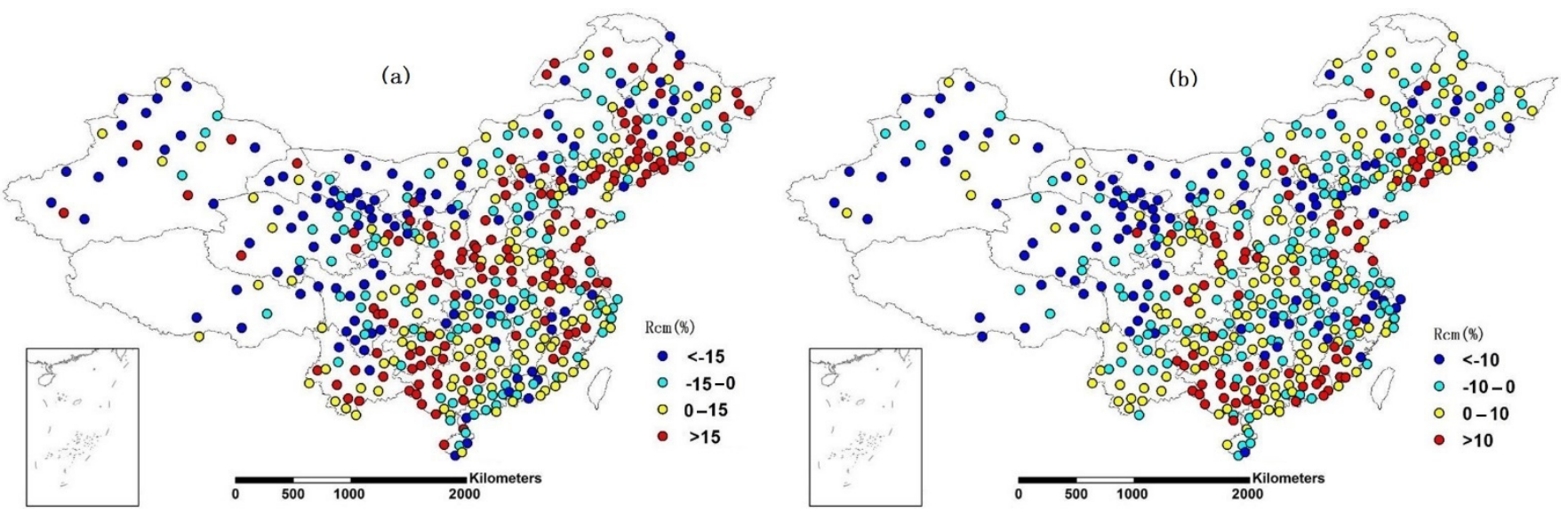

Figure 7. Spatial distribution of annual mean relative change rates of the frequency (a) and intensity (b) in EADs (1985-2007 compared to 1961-1984).

Generally, the frequency and intensity of EADs decreased in most areas of the NW and QT regions during 1985-2007, where the relative decreasing rates of many meteorological stations were greater than $10 \%$. However, the stations with increasing EAD frequency and intensity were distributed in the east areas of the Hu Huanyong line, including the four regions: SE, SW, NC, and NE. In detail, the stations with increasing EAD frequency were mainly distributed along the $\mathrm{Hu}$ Huanyong line (i.e., the areas around the line of Liaoning, Shandong, Shanxi, Shaanxi, East Sichuan, Guizhou, Guangxi, and Yunnan provinces) and the southern part of the NC region, with the relative increasing rates of EAD frequency exceeding $15 \%$ in some areas. The stations with increasing EAD intensity were mainly 
distributed in Liaoning, Shandong, Shaanxi, Yunnan, Sichuan, Guizhou, Guangdong, and Guangxi provinces, with the relative increasing rates of EAD intensity exceeding $10 \%$ at many stations in Liaoning, Guangdong, and Guangxi provinces. Since the main crop producing areas were distributed in the east area of Hu Huanyong line, it indicated that China was facing more frequent extreme agricultural droughts with stronger intensity; this was in accordance with the results of Qiu et al. [4,64], who observed that the extreme droughts induced grain loss, and the affected and damaged area of farmland increased during the past decades.

\subsubsection{Spatial Patterns of Change-Point Years in Stations with Increasing EADs}

The first change-point $|t|_{\max }$ of EAD frequency and intensity series of individual stations were detected using the moving $t$-test method. Meanwhile, its significance and trend were determined. A positive $t$ value represented a change-point with a downward trend, and vice versa. Since areas with increasing EADs tend to suffer potential threat of drought disaster and thus receive more attention, they were mainly analyzed in this section. Only stations with increasing frequency and intensity of EADs were marked in Figure 8a (frequency) and Figure 8b (intensity).
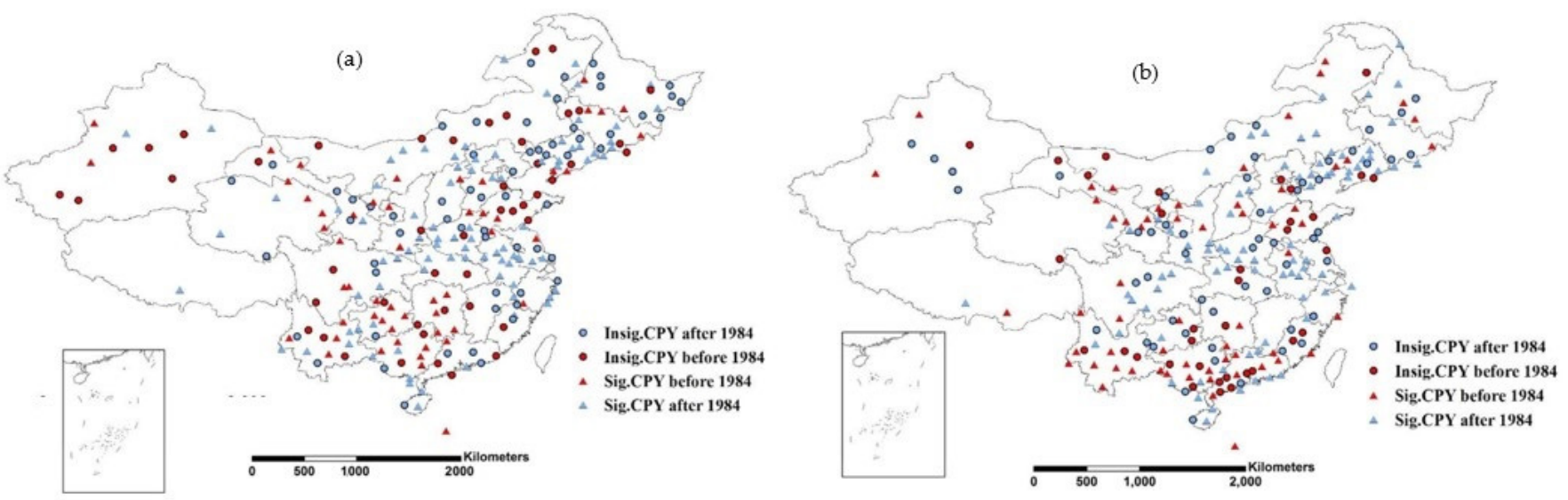

Figure 8. Spatial distribution of the increasing EADs frequency (a) intensity (b) and their corresponding change-point years.

Stations with increasing EADs were mostly distributed in the east of the $\mathrm{Hu}$ Huanyong line region (except for the areas along the Yangzi River and the northern part of the NE region), and were sporadically distributed in partial areas of southern Xinjiang, Gansu, and Ningxia provinces in the NW region. The areas where the change-point of increasing frequency in EAD occurred before 1984 mainly included Guangxi, Yunnan, and Guizhou provinces in South China (significant change-points) and Shandong Province (insignificant change-point). In contrast, the areas where the change-point of increasing frequency in EAD occurred after 1984 mainly included the southern part of the NC region (including Henan, Anhui, and Jiangsu provinces) and Liaoning Province. Stations where the changepoint of increasing intensity in EAD occurred before 1984 were mainly distributed in Guangzhou, Guangxi, and Yunnan provinces (significant change-points), partial areas of Gansu and Ningxia provinces (significant change-points), and Shandong Province (insignificant change-point). Meanwhile, the distribution of the stations where the changepoint of increasing intensity in EAD occurred after 1984 was similar to that of stations with EAD frequency variation occurring after 1984. This analysis indicated that the number and distribution range of the stations with increasing EADs were less than those of the stations with increasing EDs [65]. However, the stations with increasing EADs and increasing EDs shared a similar change trend spatially. In detail, the change-points of the two types of stations occurred earlier (generally before 1984, the red triangles in Figure 8) in southern areas but generally after 1984 (the blue triangles in Figure 8) in northern areas. 


\subsection{Case Study of Response of Grain Yields to EADs}

Based on the analysis above, the response of climatic grain yield to the frequencies and intensities of EADs was analyzed and compared with the response of climatic grain yield to the frequencies and intensities of EDs in this section, aiming to account for the necessity of building an EAD model to explore the impacts of climate extremes on crop yields. For indices of ED, the annual occurrence times was also adopted as the frequency index, and the annual maximum consecutive dry days (MCDD) was the index of intensity [17].

\subsubsection{Case Study in the NC Region}

\section{(1) Yushe County}

Owing to lag in agricultural production technology, the trend yield in Yushe County did not show an increasing trend. Therefore, EADs were directly compared with grain yields. According to Figure 9, there was a negative correlation between the grain yields and the EAD frequency and intensity (MCDWAP) in Yushe County generally. In other words, the grain yield decreased in the year when the EAD occurred more or was of longer MCDWAP. However, there were exceptions for isolated years due to the observation that the grain yield was also affected by various factors such as total annual precipitation and the enthusiasm of peasants. For example, despite no EAD occurred and the MCDWAP was relatively short in both 1990 and 1991, the grain yield was high in 1990 but very low in 1991. Combining with annual precipitation analysis, the total annual precipitation in 1990 was $718.3 \mathrm{~mm}$, which was higher than the mean annual precipitation of $535 \mathrm{~mm}$. In contrast, the total precipitation in 1991 was merely $444.4 \mathrm{~mm}$, which was lower than the mean annual precipitation. Therefore, the insufficient total annual precipitation led to the low grain yields in 1991. Meanwhile, it was also proved that 1990 witnessed abundant annual precipitation and favorable weather. In detail, the precipitation distribution in the year was consistent with the water requirement in the growing period of crops, with no obvious occurrence of extreme precipitations and EADs. Furthermore, it was necessary to combine the EAD frequency with EAD intensity for some years. For example, despite that two EADs occurred, the grain yields in 2005 decreased to some extent but was not extremely low. According to the intensity, the two EADs in 2005 were low in intensity and short in duration, with the longest one only lasting 40 days.

According to Figure 9, there was no distinct relationship between grain yields and EDs. For example, the MCDD (annual maximum consecutive dry days) lasted for up to more than 130 days in 1998, but the grain yields in the year were still high. This indicates that not all EDs induced EADs and it was necessary to combine the water requirement of crops in their different growing periods.

\section{(2) Yangcheng County}

The grain yields of Yangcheng County showed an increasing trend, and thus the response of climatic grain yield to EADs was analyzed after removing trend yield from the total grain yield. According to Figure 10(a1,a2), there was also a negative correlation between the climatic yield and EADs. The climatic yield reached the minimum and the secondary minimum in 1997 and 2001, when EADs occurred four and three times respectively, and the MCDWAP was up to 43.2 and 54.8 days, respectively. Although the MCDWAP in 1997 was shorter than that in 2001, EADs occurred four times in 1997. The interval between two EADs was short and thus there was not enough precipitation to satisfy the water requirement of crops. In 2014, although the MCDWAP was long, only one EAD occurred in Yangcheng County. As a result, the grain yield in 2014 was slightly affected. Similar to Yushe County, the response of grain yield to EDs was not notable in Yangcheng County (Figure 10(b1,b2)). Therefore, the climatic yield in the rainfed agricultural regions in Shanxi Province was mainly influenced by EADs, and extreme climatic droughts do not necessarily mean a drought-induced decrease in grain yields. 
(a1)

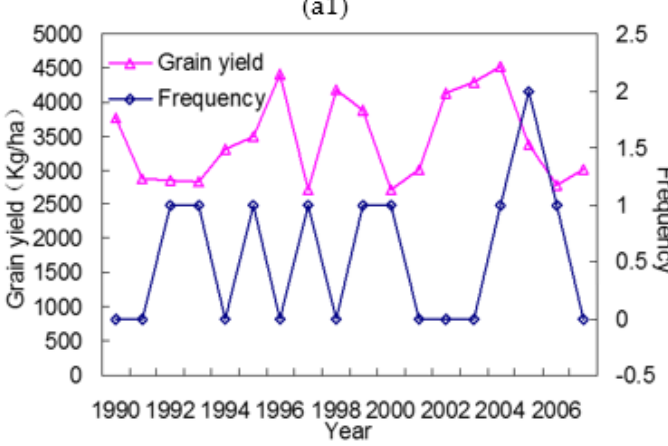

(b1)

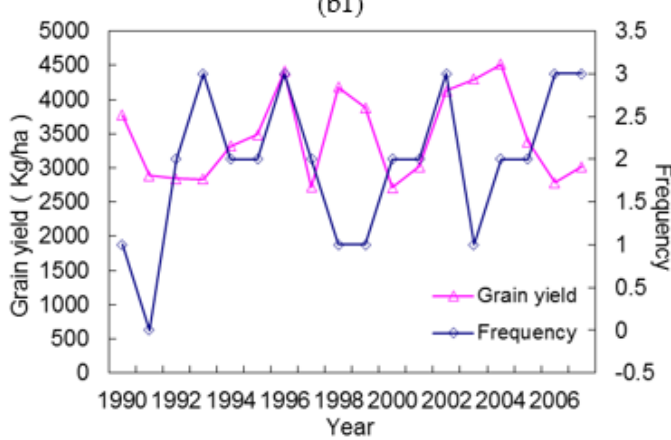

(a2)

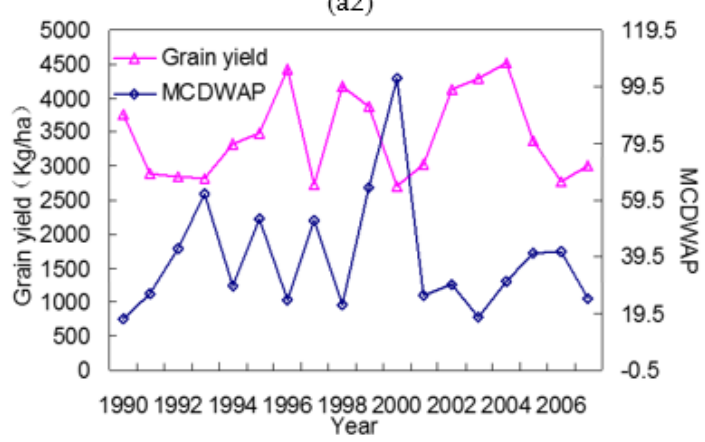

(b2)

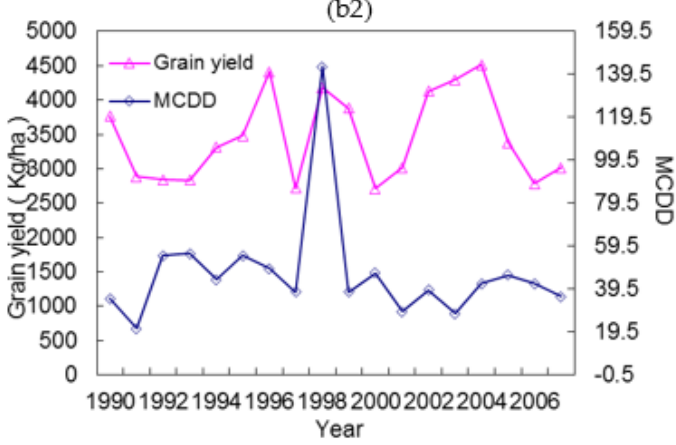

Figure 9. Response relationships of grain yield to EADs and EDs of Yushe: (a1) frequency of EADs, (a2) intensity of EADs, (b1) frequency of EDs, and (b2) intensity of EDs.

(a1)

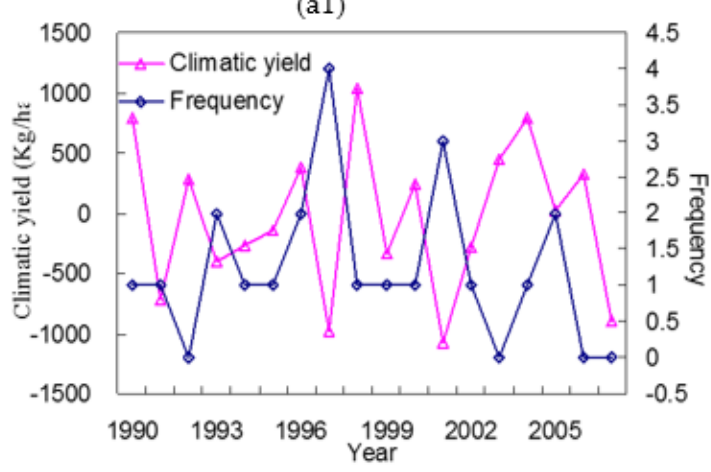

(b1)

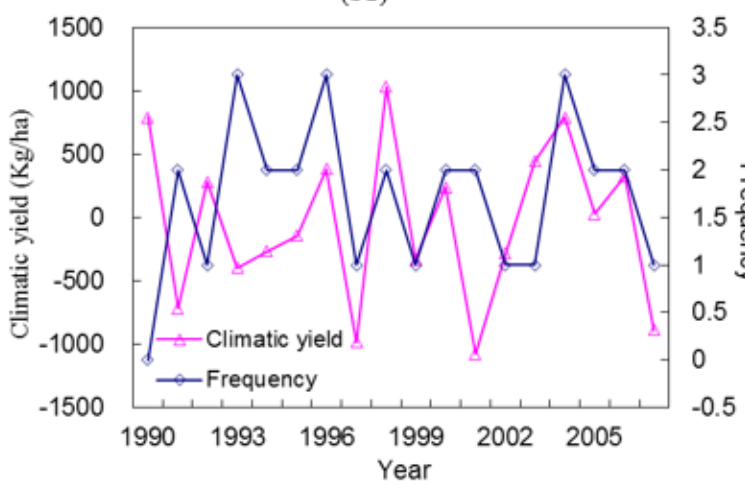

(a2)

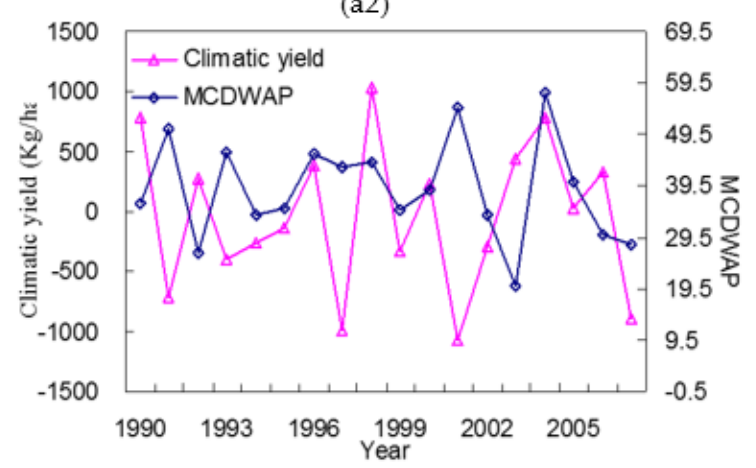

(b2)

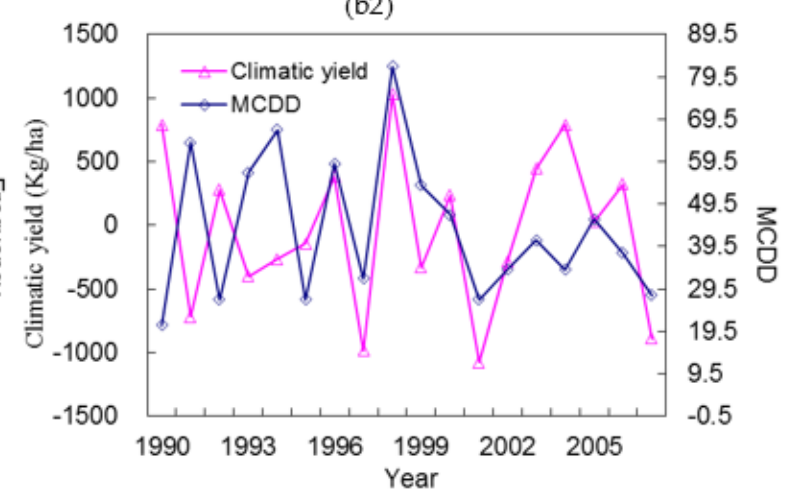

Figure 10. Response relationships of grain yield to EADs and EDs of Yangcheng: (a1) frequency of EADs, (a2) intensity of EADs, (b1) frequency of EDs, and (b2) intensity of EDs.

4.3.2. Case Study in the SW Region

(1) Bijie City 
The grain yield in Bijie City significantly increased over the years, and thus the response of the climatic yield to EADs was analyzed after removing the trend yield from the grain yields. As shown in Figure 11(a1,a2), there was also a negative correlation between the climatic yield and EADs. The climatic yield reached the minimum and the secondary minimum in 1992 and 2003, when EADs occurred four times (the highest frequency during the period) and the MCDWAP was also high. In 2005, although the MCDWAP was long, only one EAD occurred in Bijie City. As a result, the grain yield in 2005 was not significantly decreased under the impacts of droughts. On the other hand, the climatic grain yield reached a relatively high value in 2000, when no EAD occurred and the MCDWAP was very short. According to the response of climatic yield to EDs, there was also a negative correlation between the climatic yield and EDs (Figure 11(b1,b2)). However, the response of the climatic yield to EDs was poorer than the response of climatic yield to EADs in Bijie City.
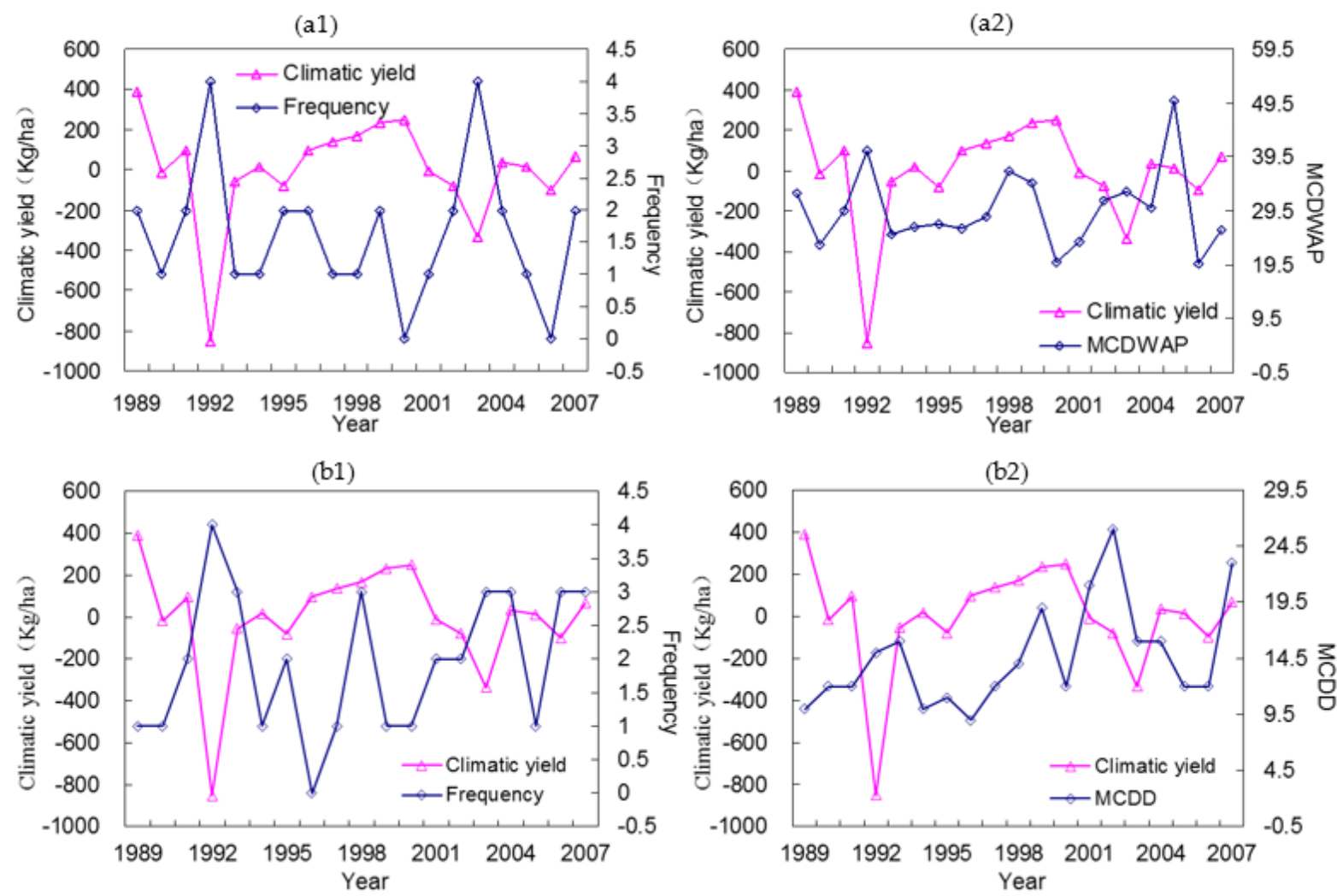

Figure 11. Response relationships of grain yield to EADs and EDs of Bijie: (a1) frequency of EADs, (a2) intensity of EADs, (b1) frequency of EDs, and (b2) intensity of EDs.

\section{(2) Anshun City}

The grain yields in Anshun City also significantly increased over the years, and thus the response of the climatic grain yield to EADs was analyzed after removing the trend yield from the grain yields. Generally, there was also a negative correlation between climatic yield and the frequency and intensity of EADs (Figure 12(a1,a2)). For example, the climatic yield reached a minimum in 2002, when EADs occurred at a high frequency and high intensity. The climatic yield was relatively low in 1992, when EADs occurred at a relatively high frequency, but the MCDWAP was not long. The specific reasons are yet to be clarified. It should be noted that the rain-fed agriculture did not account for $100 \%$ of the agriculture in the whole Anshun City. Furthermore, Anshun has developed minor grain crops and agricultural products with regional characteristics in recent years. Therefore, the grain yields in the city may have been affected more by human factors, e.g., the policy factors, thus the negative correlation between the grain yield and EADs was relatively weaker than 
that of Beijie city. According to Figure 12(b1,b2), there was no distinct relationship between grain yields and EDs.

(a1)

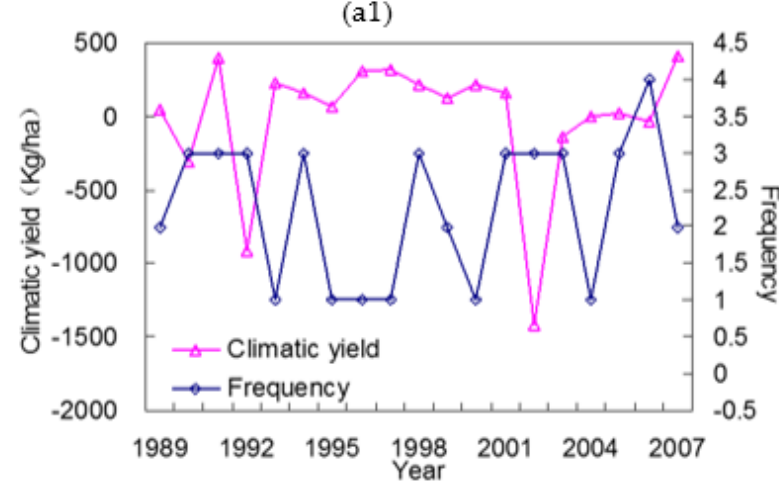

(b1)

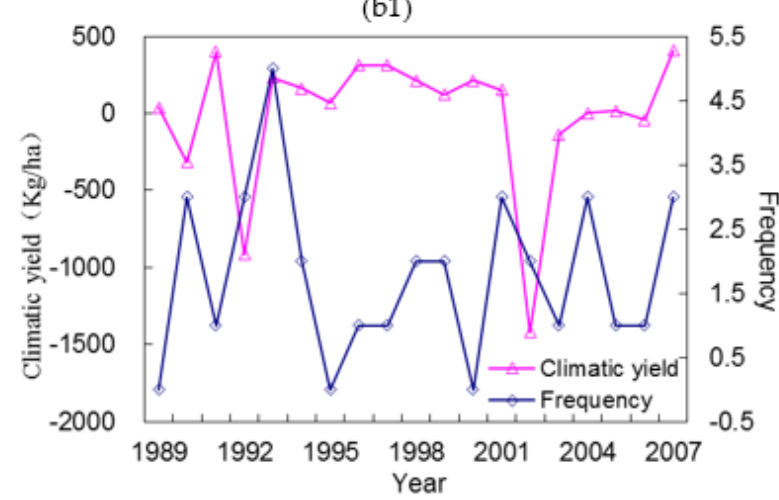

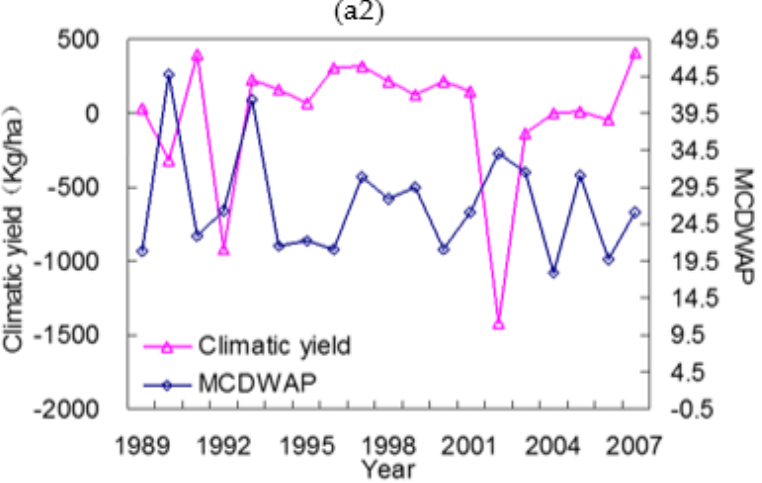

(b2)

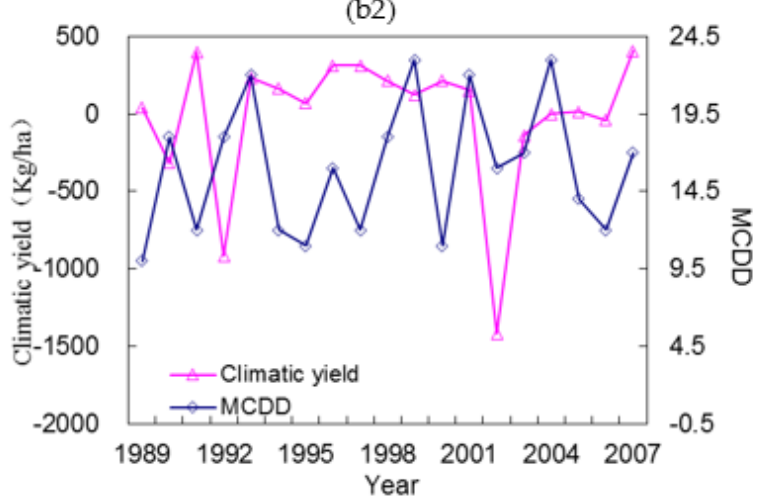

Figure 12. Response relationships of grain yield to EADs and EDs of Anshun: (a1) frequency of EADs, (a2) intensity of EADs, (b1) frequency of EDs, and (b2) intensity of EDs.

\subsubsection{Case Study in SE Region}

\section{(1) Meixian District}

Generally, there was also a negative correlation between the climatic yield and the frequency and intensity of EADs in Meixian District (Figure 13a), i.e., low climatic yields often occurred in the year with relatively higher frequency and stronger intensity of EADs, e.g., in the years 1992 and 2007. Additionally, in the years with low frequency of intensity of EADs during 1999-2001 the climatic yields were relatively high. Furthermore, the climatic yield showed a decreasing trend after 2000, while the frequency and intensity of EADs increased.

\section{(2) Wuhua County}

Generally, there was also a negative correlation between the climatic yield and the frequency and intensity of EADs in Wuhua County (Figure 14a), i.e., relatively low climatic yields often occurred in the years with the relatively higher frequency and intensity of EADs, e.g., in the years 1992, 1997, and 2007. Additionally, in the years with the lower frequency and weaker intensity of EADs during 2000-2003 the climatic yields were relatively high. Furthermore, the climatic yield showed a decreasing trend after 2000, while the frequency and intensity of EADs increased. 
(a1)

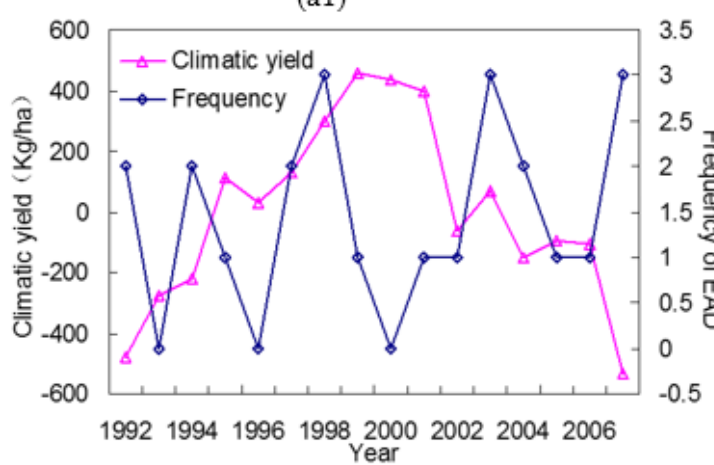

(b1)

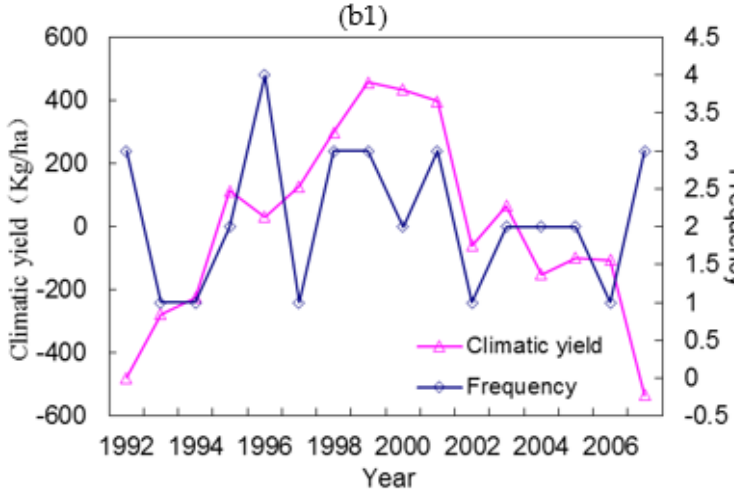

(a2)

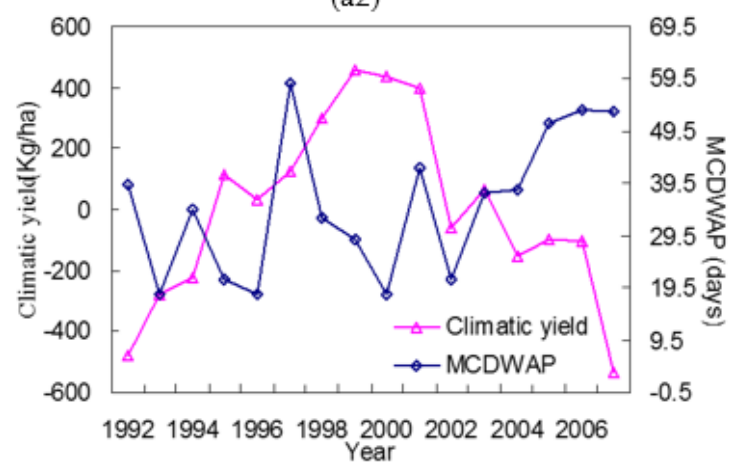

(b2)

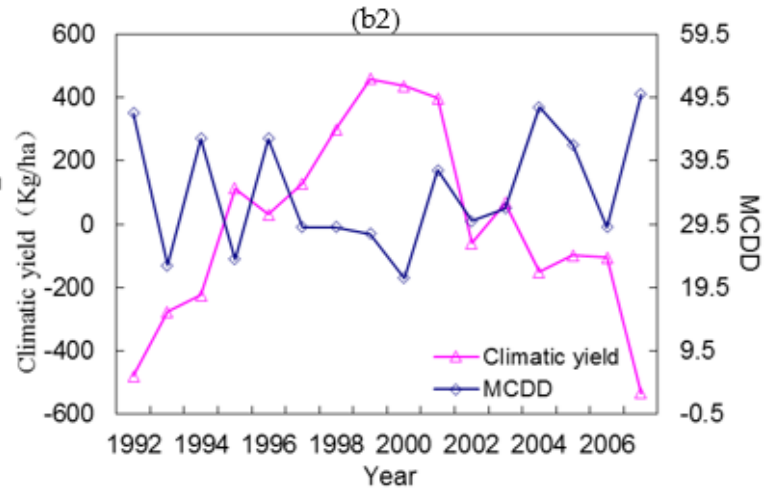

Figure 13. Response relationships of grain yield to EADs and EDs of Meixian: (a1) frequency of EADs, (a2) intensity of EADs, (b1) frequency of EDs, and (b2) intensity of EDs.

(a1)

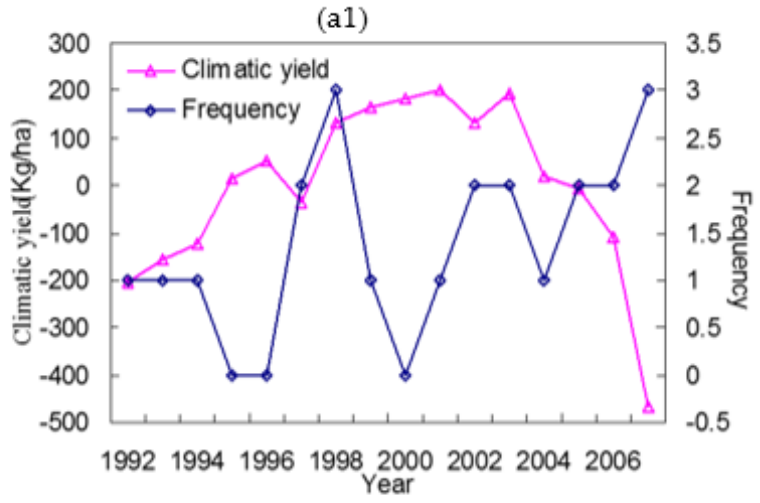

(b1)

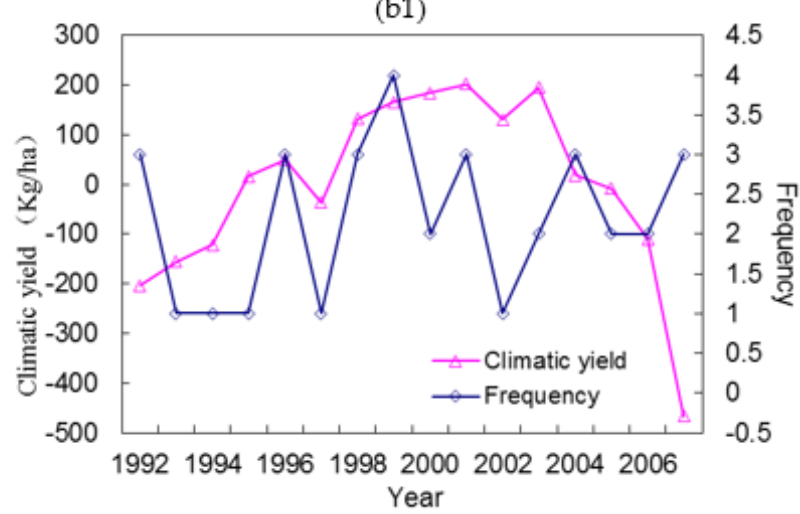

(a2)

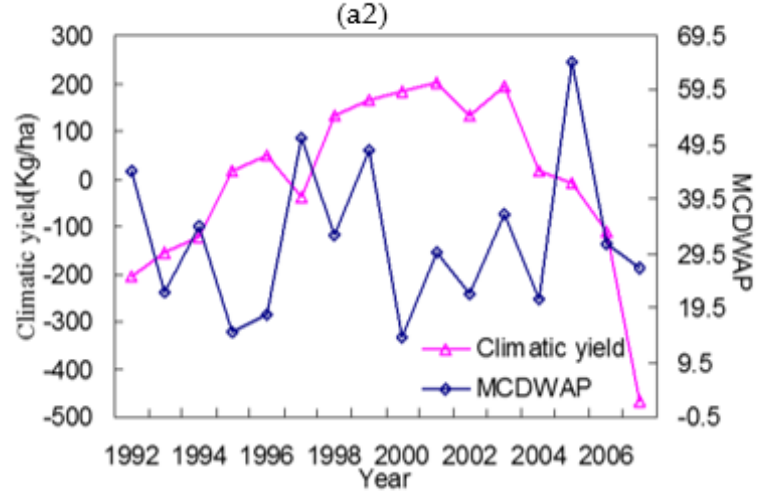

(b2)

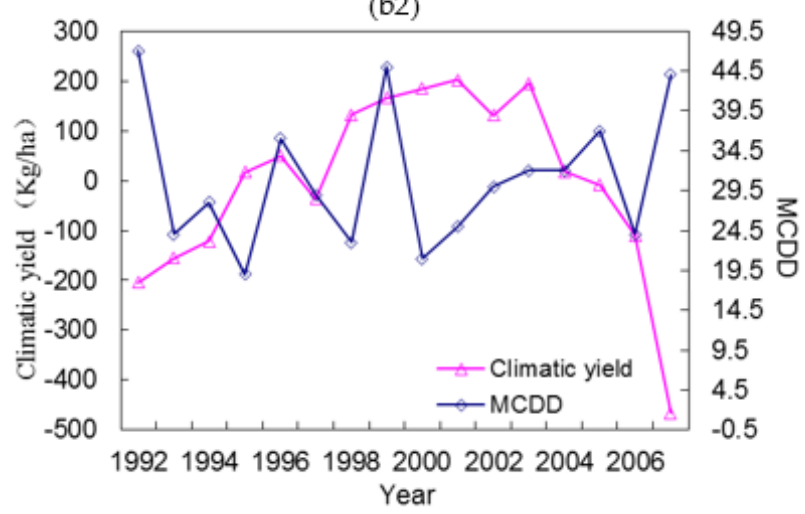

Figure 14. Response relationships of grain yield to EADs and EDs of Wuhua: (a1) frequency of EADs, (a2) intensity of EADs, (b1) frequency of EDs, and (b2) intensity of EDs. 


\section{Discussion}

\subsection{Regional Mean Change Rates of EADs and EDs}

For the EADs of the meteorological stations in the six climate regions, the regional mean relative change rates were calculated and compared with ED change rates in our previous paper [17]. Generally, the relative change rates of the EAD frequencies and intensities in the four regions of NE, NC, SC, and WC were positive in the research period (Table 3), and the increasing change rates of frequency were obviously greater than that of intensity. Among the four regions, the relative increase rates reached the first two maximum values in NC and SW regions, the values of the frequencies and intensities were $11.26 \%$ and $2.22 \%$ in NC region, respectively, and $9.27 \%$ and $2.65 \%$ in SW region respectively. These were followed by the SE region, both in the frequency and intensity, whose values were $7.13 \%$ and $1.78 \%$ respectively. This indicated that the EADs in major agricultural producing areas of China tended to increase in frequency with stronger intensity. However, their relative changes rates were smaller than those of EDs (Table 3), indicating that extreme climatic droughts do not always have a serious impact on agriculture in these areas despite the significantly increasing frequency and intensity in ED. In contrast, the relative increasing rates of EAD frequency and intensity in NE region were higher than those of EDs. This indicated that climatic drought was more likely to pose threat to agriculture production and grain yield in NE (mainly including Liaoning). These were in accordance with the conclusion of Du et al. (2020) [64]. Overall, study on EADs is of great necessity due to climatic extreme droughts (ED) could not represent that of EAD (extreme agro-climatic droughts) in the research field of climate change impact and adaptation.

Table 3. Comparison of relative change rates between EADs and EDs.

\begin{tabular}{ccccc}
\hline & $\boldsymbol{R}_{\boldsymbol{c m}}$ of EADF (\%) & $\boldsymbol{R}_{\boldsymbol{c m}}$ of EADI (\%) & $\boldsymbol{R}_{\boldsymbol{c m}}$ of EDF (\%) & $\boldsymbol{R}_{\boldsymbol{c m}}$ of EDI (\%) \\
\hline NE & 5.67 & 0.67 & 4.99 & -0.92 \\
NC & 11.26 & 2.22 & 26.43 & 2.82 \\
SE & 7.13 & 1.78 & 64.24 & 14.73 \\
SW & 9.27 & 2.65 & 98.08 & 25.93 \\
QT & -17.78 & -12.00 & -1.83 & -11.21 \\
NW & -16.37 & -10.39 & -9.30 & -4.51 \\
\hline
\end{tabular}

Note: EADF and EADI represent the frequency and intensity of EAD; EDF and EDI represent that of ED.

\subsection{Differences in Response Relationship of Grain Yield to EAD and ED}

In order to investigate the responses of grain yield to ED and EAD more clearly, we calculated the correlation coefficients and their significances of climatic grain yield and extreme droughts (including both ED and EAD) (Table 4). There was an inverse correlation between the frequency of EAD and grain yield in all the regions. The correlation coefficients between grain yields and the frequency of EAD were mostly greater than that of ED, and the significance $p$ values were mostly lower than that of ED. This indicated that the EAD threshold model was more available in the study of impact of extreme droughts on grain yield due to frequency series that were obtained based on the annual counts of the threshold exceedance. There was also an inverse correlation between the intensity, the correlation coefficients between grain yields and the intensity of EAD were mostly greater than that of ED, and the significance $p$ values were mostly lower than that of ED in the NC and SW regions, though the correlation coefficients and the significances were generally lower than that of frequency. This showed that the index of CDWAP was more available than the $\mathrm{CDD}$, which was merely established from the climatic prospective. Overall, extreme climatic droughts may not necessarily cause agricultural drought, while EAD, which was analyzed based on the index in combination with characteristics of crop growing period and critical period of crop water requirement, was very necessary in the research field of the impacts of extreme events on grain yield. 
Table 4. Correlation coefficient $(\mathrm{R})$ and its significance $(p)$ of grain yield and extreme droughts (both ED and EAD).

\begin{tabular}{|c|c|c|c|c|c|c|c|}
\hline \multirow{2}{*}{\multicolumn{2}{|c|}{$\mathbf{R}(p)$}} & \multicolumn{2}{|c|}{ NC Region } & \multicolumn{2}{|c|}{ SW Region } & \multicolumn{2}{|c|}{ SE Region } \\
\hline & & Yushe & Yangcheng & Bijie & Anshun & Meixian & Wuhua \\
\hline \multirow{2}{*}{ Fr. } & ED & $-0.13(0.60)$ & $0.08(0.74)$ & $-0.63(0.01)$ & $-0.14(0.56)$ & $0.17(0.52)$ & $0.08(0.75)$ \\
\hline & EAD & $-0.30(0.05)$ & $-0.45(0.06)$ & $-0.59(0.01)$ & $-0.37(0.11)$ & $-0.27(0.31)$ & $-0.29(0.28)$ \\
\hline \multirow[b]{2}{*}{ In. } & ED & $-0.23(0.36)$ & $0.17(0.49)$ & $-0.15(0.52)$ & $-0.10(0.68)$ & $-0.59(0.02)$ & $-0.37(0.16)$ \\
\hline & EAD & $-0.47(0.23)$ & $-0.12(0.63)$ & $-0.24(0.32)$ & $-0.29(0.23)$ & $-0.27(0.30)$ & $-0.06(0.81)$ \\
\hline
\end{tabular}

However, the correlation and its significance of grain yield and EAD in SE region were generally lower than the other regions, especially in intensity of EAD. The attributions may be as follows. (1) The threshold model of the EADs was yet to be ameliorated. The regional mean values were adopted for cropping patterns and the parameters of the different growing periods in each agricultural region, which had a small deviation from the actual situation. Thus, the negative correlations between the grain yields and the EADs were stronger in the agricultural areas with higher rain-fed degree and higher planting proportion of the main grain crops, while there was a decrease tendency in the main grain yield in SE region from around 2002 due to the rapid economic development, which induced increased planting and development of a cash crop, so weaker correlations showed. (2) The increase in cash crop led to a relative decrease in the production of and attention on the main grain yield; thus, there was no more trend of continuous growth in main grain yield from around 2002. Therefore, this may have led to a small deviation in the decomposition of grain yield into trend yield and climatic yield.

Furthermore, due to the climate, grain yield may include influences not only from extreme drought, but also by the annual mean precipitation, other climate extremes, and short-term policies [62,63]; some of the correlation coefficients were relatively low. However, the extreme droughts accounted for the highest proportion, $79 \%$, among all the agro-meteorological disasters [6], and the annual precipitation was generally low in the years with high frequency or/and intensity of EAD, so the influences of EAD on the grain yield may partly include that of annual precipitation. Therefore, the result was also effective.

\section{Conclusions}

(1) A threshold determination model of EADs was built based on the CDF of an agricultural drought index - the CDWAP. The CDWAP was established by combining meteorological data with the characteristics of the cropping patterns and the water requirement in different growing periods of crops. The CDF of CDWAP was obtained based on the relationship of CDWAP and its occurrence frequency. This model provides a basis for the impact study of climate extremes on grain yield reduction.

(2) The threshold value of EADs in China gradually increased from southeast to northwest. The stations of the highest value were located in the desert areas in Northwest China, with the CDWAP more than 60 days, while the lowest value was in the middle reaches of the Yangzi River, with the CDWAP less than 16 days. The value in North China was between 20-40 days, and that in the southern humid area was generally less than 20 days.

(3) The frequency and intensity of the EADs were on increasing trends in most of the regions in China except the QT and NW regions. The NC and SW regions showed the two highest increasing rates of the EADs; the frequencies and intensities of them were $11.3 \%$ and $2.2 \%$ for NC region, and $9.3 \%, 2.7 \%$ for SW region, respectively, but all were lower than the relative change rates of the EDs. Furthermore, the increasing rate of the frequency and intensity of EADs in NE China were a little higher than 
the results of the EDs, with the increasing rates of frequency and intensity in EADs being $5.7 \%$ and $0.7 \%$, respectively.

(4) There was a negative correlation between the grain yields and the EAD frequency and intensity; i.e., the low climatic yields often occurred in the year with relatively higher frequency or/and stronger intensity of EADs. The correlation between them became stronger in the more rain-fed areas and larger planting proportion of the main grain crops (wheat, rice, and maize) due to the premise of the threshold model.

This was only a preliminary analysis of the impact of extreme climate drought events on grain yield. The implication of the model will be expanded to all the agricultural areas to analyze the quantitative impacts of extreme climate drought events on grain yield, combining the drought extremes with the mean state of climate change, other climate extremes, and short-term policies, among others, in future study.

Author Contributions: Conceptualization, M.L. and Y.G.; methodology, M.L.; validation, Y.W. and J.H.; formal analysis, M.L.; data curation, Y.G.; writing—original draft preparation, M.L.; writingreview and editing, Y.G. and Y.W.; visualization, J.H.; project administration, Y.G.; funding acquisition, M.L. and Y.G. All authors have read and agreed to the published version of the manuscript.

Funding: This research was funded by the National Natural Science Foundation of China "Response mechanism of groundwater level anomalous changes to extreme dry climate and irrigation activities in Minqin Oasis", grant number 41902262; the Fund of Key Laboratory of Agricultural Water Resources of CAS "Study on Global Changes in Agricultural Use/Supply and Its Impacts on Food Security", grant number ZDKT201801; the Natural Science Foundation of Hebei Province-China (No. D2019503028); and the Geological Survey Project of China (grant number DD20190349).

Institutional Review Board Statement: Not applicable.

Informed Consent Statement: Not applicable.

Data Availability Statement: Data used in this study is available upon request.

Acknowledgments: We acknowledge Yanjun Shen and Yongqing Qi from the Center for Agricultural Resources Research, Institute of Genetics and Developmental Biology, Chinese Academy of Sciences, for their help in guidance and supervision. We also thank the three anonymous reviewers for their valuable comments and suggestions.

Conflicts of Interest: The authors declare no conflict of interest.

\section{References}

1. IPCC. Climate Change 2013: The Physical Science Basis; Cambridge University Press: Cambridge, UK, 2013.

2. IPCC. Climate Change 2021: The Physical Science Basis; Cambridge University Press: Cambridge, UK, 2021.

3. Zheng, D.; Li, M.; Huo, Z. Agricultural Disasters and Reduction Countermeasures; China Agricultural University Press: Beijing, China, 2013.

4. Qiu, H.; Cao, M.; Hao, J.; Wang, Y.; Wang, Y. Relationship between Frequency and Magnitude of Drought Damage in China in 1950-2010. Sci. Geogr. Sin. 2013, 33, 576-580.

5. Li, M.; Li, S.; Li, Y. Studies on Drought in the Past 50 Years in China. Chin. J. Agrometeorol. 2003, 24, 7-10.

6. Zhang, Z.; Wang, P.; Chen, Y.; Zhang, S.; Tao, F.; Liu, X. Spatial pattern and decadal change of agro-meteorological disasters in the main wheat production area of China during 1991-2009. J. Geogr. Sci. 2014, 24, 387-396. [CrossRef]

7. Meng, L.; Fordb, T.; Guo, Y. Logistic regression analysis of drought persistence in East China. Int. J. Climatol. 2017, 37, 1444-1455. [CrossRef]

8. Zhang, J.; Shen, Y.J. Spatio-temporal variations in extreme drought in China during 1961-2015. J. Geogr. Sci. 2019, 29, 67-83. [CrossRef]

9. Palmer, W.C. Meteorologieal Drought; Research Pape No 45; US Weather Bureau, NOAA Library and Information Service Division: Washington, DC, USA, 1965.

10. Dai, A.; Trenberth, K.E.; Qian, T. A Global Dataset of Palmer Drought Severity Index for 1870-2002: Relationship with Soil Moisture and Effects of Surface Warming. J. Hydrometeorol. 2004, 5, 1117-1130. [CrossRef]

11. Vicente-Serrano, S.M.; Beguería, S.; López-Moreno, J.I. A Multiscalar Drought Index Sensitive to Global Warming: The Standardized Precipitation Evapotranspiration Index. J. Clim. 2010, 23, 1696-1718. [CrossRef] 
12. Loukas, A.; Vasiliades, L.; Spiliotopoulos, M.; Bampzelis, D.; Dalezios, N.R. An Assessment of Regional Droughts in Greece Using Two Meteorological Drought Indices, Comecap 2002. In Proceedings of the 6th Hellenic Conference in Meteorology-Climatology and Atmospheric Physics, Ioannina, Greece, 26-28 September 2002.

13. Livada, I.; Assimakopoulos, V.D. Spatial and temporal analysis of drought in greece using the Standardized Precipitation Index (SPI). Theor. Appl. Climatol. 2007, 89, 143-153. [CrossRef]

14. Alexander, L.V.; Zhang, X.; Peterson, T.C.; Caesar, J.; Gleason, B.; Tank, A.M.G.K.; Haylock, M.; Collins, D.; Trewin, B.; Rahimzadeh, F. Global observed changes in daily climate extremes of temperature and precipitation. J. Geophys. Res. Atmos. 2006, 111, 1042-1063. [CrossRef]

15. Zhang, X.; Alexander, L.; Hegerl, G.C.; Jones, P.; Tank, A.K.; Peterson, T.C.; Trewin, B.; Zwiers, F.W. Indices for monitoring changes in extremes based on daily temperature and precipitation data. Wiley Interdiscip. Rev. Clim. Change 2011, 2, 851-870. [CrossRef]

16. Alexander, L.V. Global observed long-term changes in temperature and precipitation extremes: A review of progress and limitations in IPCC assessments and beyond. Weather Clim. Extrem. 2016, 11, 4-16. [CrossRef]

17. Liu, M.; Shen, Y.; Qi, Y.; Wang, Y. Changes in Precipitation and Drought Extremes over the Past Half Century in China. Atmosphere 2019, 10, 203. [CrossRef]

18. Asseng, S.; Martre, P.; Maiorano, A.; Rötter, R.P.; Leary, G.J.O. Climate change impact and adaptation for wheat protein. Glob. Change Biol. 2019, 25, 155-193. [CrossRef]

19. Xiong, W.; Lin, E.; Ju, H.; Xu, Y. A Study of the Threshold of Climate Change Impact on Food Production in China. Adv. Clim. Change Res. 2005, 1, 84-87.

20. Xiong, W.; Ju, H.; Xu, Y.; Lin, E. The Threshold of Temperature Increase Due to Climate Change for Chinese Agriculture and Its Uncertainties. Adv. Earth Sci. 2006, 021, 70-76.

21. Tian, Z.; Liu, J.; Cao, M. Simulation of the Impact of Climate Change on Chinese Wheat Production in Huang-Huai-Hai Plain. J. Nat. Resour. 2006, 21, 598-607.

22. Xiong, W.; Yang, J.; Lin, E.; Xu, Y. The Projection of Maize Yield in China under Climate Change Scenarios. Adv. Earth Sci. 2008, 23, 1092-1101.

23. Xiong, W.; Lin, E.; Jiang, J.; Li, Y.; Xu, Y. An Integrated Analysis of Impact Factors in Determining China's Future Grain Production. Acta Geogr. Sin. 2010, 65, 397-406.

24. Meza, F.J.; Silva, D. Dynamic adaptation of maize and wheat production to climate change. Clim. Change 2009, 94, 143-156. [CrossRef]

25. Hlavinka, P.; Trnka, M.; Semerádová, D.; Dubrovsky, M.; Alud, Z.; Mo Ny, M. Effect of drought on yield variability of key crops in Czech Republic. Agric. For. Meteorol. 2009, 149, 431-442. [CrossRef]

26. Moriondo, M.; Giannakopoulos, C.; Bindi, M. Climate change impact assessment: The role of climate extremes in crop yield simulation. Clim. Chang. 2011, 104, 679-701. [CrossRef]

27. Zhou, S.; Zhou, W.; Lin, G.; Qiao, H. The Impact of Future Climate Change on China's Food Security. J. Nanjing Agric. Univ. 2013, $1,61-70$.

28. Li, K.; He, X.; Xu, Y.; Zheng, D. Study on Classification of Adaptation Technologies to Climate Change in China. China Popul. Resour. Environ. 2016, 26, 18-26.

29. Liu, L.; Liu, X.; Lun, F.; Wu, L. Research on China's Food Security under Global Climate Change Background. J. Nat. Resour. 2018, 33, 927-939.

30. Guo, J.; Zhang, B.; Gao, J.; Peng, J.; Luo, R. Advances on the impacts of climate change on agro-climatic resources and agricultural production in China. J. North. Agric. 2019, 47, 105-113.

31. Tao, F.; Yokozawa, M.; Hayashi, Y.; Lin, E. Future climate change, the agricultural water cycle, and agricultural production in China. Agric. Ecosyst. Environ. 2003, 95, 203-215. [CrossRef]

32. Trnka, M.; Dubrovsk, M.; Alud, Z. Climate Change Impacts and Adaptation Strategies in Spring Barley Production in the Czech Republic. Clim. Chang. 2004, 64, 227-255. [CrossRef]

33. Zhao, R.; Wang, H.; Dong, Y. Impact of climate change on grain yield and its trend across Guanzhong region. Chin. J. Eco-Agric. 2020, 28, 467-479.

34. Meng, Y.; Ba, Y.; Sun, Y.; Yuan, J. Impact of Climate Change on Maize Planting Area. Agric. Technol. 2020, 40, 109-111.

35. Pang, Y.; Chen, C.; Xu, F.; Guo, X. Impact of climate change on potential productivities of main grain crops in the Sichuan Basin. Chin. J. Eco-Agric. 2020, 28, 17-28.

36. Chen, C.; Pang, Y.; Xu, F.; Guo, X. Dry-wet evolution and its influencing factors in single cropping rice growing season in Southwest China. Chin. J. Eco-Agric. 2020, 28, 492-502.

37. Cai, X.; Liang, G. Characteristics of Climate Change in Shuozhou City of Shanxi Province in 2019 Analysis of Impact on Crops. J. Agric. Catastrophol. 2020, 10, 134-136.

38. Bai, F.; Yang, X.; Liu, Z.; Sun, S. Effects of sowing dates on grain yield of spring maize in the Three-Province of the Northeast China under climate change. Chin. J. Eco-Agric. 2020, 28, 480-491.

39. Ling, X.; Zhang, Z.; Zhai, J.; Ye, S. A review for impacts of climate change on rice production in China. Acta Agron. Sin. 2019, 45, 323-334. [CrossRef] 
40. Kheir, A.M.S.; Baroudy, A.E.; Aiad, M.A.; Zoghdan, M.G.; Abd El-Aziz, M.A.; Ali, M.G.M.; Fullen, M.A. Impacts of rising temperature, carbon dioxide concentration and sea level on wheat production in North Nile delta. Sci. Total Environ. 2018, 651 Pt 2, 3161-3173. [CrossRef]

41. Kheir, A.; Marwa Gamal Mohamed Ali, M.M.I.A. Climate change impact and adaptation on wheat yield, water use and water use efficiency at North Nile Delta. Front. Earth Sci. 2020, 14, 522-536.

42. Ding, Z.; Ali, E.F.; Elmahdy, A.M.; Ragab, K.E. Modeling the combined impacts of deficit irrigation, rising temperature and compost application on wheat yield and water productivity. Agric. Water Manag. 2021, 244, 106626. [CrossRef]

43. Asseng, S.; Kheir, A.; Kassie, B.T.; Hoogenboom, G. Can Egypt become self-sufficient in wheat? Environ. Res. Lett. 2018, 13, 094012. [CrossRef]

44. Zhang, Y.; Wang, S.; Wang, F. Research on the Possible Effect of Climate Change on Growth and Yield of Wheat in China. Q. J. Appl. Meteorol. 2000, 11, 264-270.

45. Alud, Z.; Dubrovsky, M. Modelling climate change impacts on maize growth and development in the Czech Republic Theor. Appl. Climatol. 2002, 72, 85-102.

46. Yao, F.; Qin, P.; Zhang, J.; Lin, E. Uncertainties in assessing the effect of climate change on agriculture using model simulation and uncertainty processing methods. Chin. Sci. Bull. 2011, 56, 547-555. [CrossRef]

47. Zhang, S.; Li, Q.; Ji, L.; Ma, J.; Wang, Z.; He, S.; Li, G. Climate Change and Its Impact on Potential Productivity: In Western Chongqing During 1970-2014. Chin. Agric. Sci. Bull. 2018, 034, 112-117.

48. Yang, Z. Influence of extreme climate on food production security in China and its safeguard measures. Mod. Agric. Sci. Technol. 2010, 21, 329-330. [CrossRef]

49. Han, L.; Zhang, Q.; Cheng, Y.; Chen, P. Research progress of agriculture drought disaster risk and prospect. J. Arid Land Resour. Environ. 2020, 34, 97-102.

50. Ma, X.; Yang, S.; Shi, H.; Qin, L. An Analysis of the Influence of Climate Change on Crop Water Requirement in Northern Regions of China. Hans J. Agric. Sci. 2020, 10, 798-802.

51. Kong, L.; Fu, S.; Han, X.; Liu, W. Spatiotemporal Variation of Long-term Meteorological Drought and Its Impacts on Grain Yield in Shaanxi Province Based on the Traditional Arid-Wet Index. Res. Soil Water Conserv. 2020, 27, 159-167.

52. Peel, M.C.; Finlayson, B.L.; Mcmahon, T.A. Updated world map of the Köppen-Geiger climate classification. Hydrol. Earth Syst. Sci. 2007, 11, 259-263. [CrossRef]

53. Wenyu, Y.; Naimei, T. Crop Cultivation: Book of Southern Part (Version 2); China Agricultural Press: Beijing, China, 2011.

54. Yu, Z. Crop Cultivation: Book of Northern Part (Version 2); China Agricultural Press: Beijing, China, 2013.

55. Liu, M. An Atlas of Physical Geography of China (Version 2); SinoMaps Press: Beijing, China, 1998.

56. Li, Y. Agricultural Regionalization in China; China Agricultural Science and Technology Press: Beijing, China, 1997.

57. Hu, L.; Ding, Y. Crop Cultivation: Version 2; Higher Education Press: Beijing, China, 2019.

58. Available online: https://www.fao.org/aquastat/en/geospatial-information/global-maps-irrigated-areas/latest-version (accessed on 11 March 2011).

59. Xue, Y.; Smith, T.M.; Reynolds, R.W. Interdecadal Changes of 30Yr SST Normals during 1871-2000. J. Clim. 2003, 16, 1601-1612. [CrossRef]

60. Brown, L. The Conditional Level of Student's $t$ Test. Ann. Math. Stat. 1967, 38, 1068-1071. [CrossRef]

61. Xu, L.; Ying, G.; Liu, M.; Hu, Q.; Chen, F. Analysis of Temperature Trends and Change Points in the Haihe River Basin Over the Last 50 Years. Resour. Sci. 2011, 33, 995-1001.

62. Jiang, S.; Jin, J.; Xu, H.; Zhou, Y.; Wang, Y. Fluctuations effect analysis of grain yield per hectare based on empirical mode decomposition and set pair analysis. Trans. Chin. Soc. Agric. Eng. 2013, 29, 213-221.

63. Liu, Z.; Huang, F.; Li, B. Analysis on characteristics and influential factors of grain yield fluctuation in China based on empirical mode decomposition. Trans. Chin. Soc. Agric. Eng. 2015, 31, 7-13.

64. Du, J. Effects of Drought on Grain Yield of Main Grain Producing Areas in China and Countermeasures for Drought Resistance. Ph.D. Thesis, Chinese Academy of Agricultural Sciences, Beijing, China, 2020.

65. Liu, M.; Liu, P.; Guo, Y.; Wang, Y.; Yu, Y. Change-Point Analysis of Precipitation and Drought Extremes in China over the Past 50 Years. Atmosphere 2019, 11, 11. [CrossRef] 